\title{
Influence of Vertical Equivalent Damping Ratio on Seismic Isolation Effectiveness of Nuclear Reactor Building
}

\author{
Xiuyun Zhu ${ }^{1,2, *}$, Jianbo Li ${ }^{1}$, Gao Lin ${ }^{1}$ and Rong Pan ${ }^{2}$ \\ 1 Faculty of Infrastructure Engineering, Dalian University of Technology, Dalian 116024, China; \\ jianboli@dlut.edu.cn (J.L.); gaolin@dlut.edu.cn (G.L.) \\ 2 Nuclear and Radiation Safety Center, Ministry of Ecology and Environment, Beijing 100082, China; \\ panrong@chinansc.cn \\ * Correspondence: zhuxiuyun@chinansc.cn or lyzhuxiuyun@163.com
}

check for updates

Citation: Zhu, X.; Li, J.; Lin, G.; Pan, R. Influence of Vertical Equivalent Damping Ratio on Seismic Isolation Effectiveness of Nuclear Reactor Building. Energies 2021, 14, 4602. https://doi.org/10.3390/en14154602

Academic Editors: Rosa Lo Frano and Mariano Tarantino

Received: 17 June 2021

Accepted: 13 July 2021

Published: 29 July 2021

Publisher's Note: MDPI stays neutral with regard to jurisdictional claims in published maps and institutional affiliations.

Copyright: (c) 2021 by the authors. Licensee MDPI, Basel, Switzerland. This article is an open access article distributed under the terms and conditions of the Creative Commons Attribution (CC BY) license (https:// creativecommons.org/licenses/by/ $4.0 /)$.

\begin{abstract}
This paper aimed at evaluating the influence of different vertical equivalent damping ratios of a 3-dimensional combined isolation bearing (3D-CIB) as regards seismic response and isolation effectiveness. A comparative study of the seismic response in terms of acceleration floor response spectra (FRS), peak acceleration, displacement response of the nuclear reactor building, and dynamic response of the 3D-CIB was carried out. The results showed that: (1) the horizontal FRS is slightly influenced by the vertical equivalent damping ratio of 3D-CIB, whereas the increase of the vertical equivalent damping ratio has a significant effect on reducing the vertical FRS; (2) the peak vertical acceleration increased with the decrease in the vertical equivalent damping ratios of 3D-CIB and the difference of peak accelerations calculated by the damping ratio of 20 and $25 \%$ is within $10 \%$; (3) the increase of the vertical equivalent damping ratio is capable of reducing the horizontal displacement and the rocking effect of the superstructure, and effectively controlling the vertical displacement amplitude; and (4) the vertical equivalent damping ratio of 3D-CIB has a slight effect on its axial force. Consequently, it is demonstrated that the increase of the vertical equivalent damping ratio is advantageous for isolation effectiveness. From the view of displacement control, it is suggested that the $3 \mathrm{D}-\mathrm{CIB}$ with the vertical an equivalent damping ratio of $15 \sim 20 \%$ is appropriate and acceptable.
\end{abstract}

Keywords: 3D base-seismic isolation; 3-dimensional combined isolation bearing (3D-CIB); vertical equivalent damping ratio; isolation effectiveness

\section{Introduction}

Earthquakes are one of the most potentially destructive natural disasters, causing great loss of property and life. In the traditional seismic design of structures, seismic resistance is enhanced by increasing the strength of the structural components. In the past, several kinds of new passive and active techniques have been developed to reduce the disaster of earthquakes, with base isolation a popular seismic protection technology whereby some bearings with low stiffness are interposed between the structure and the ground [1-4]. In recent years, innovative methods have been developed to increase the efficiency and safety of structures against earthquakes. Since the seismic base isolation system can decrease the total energy transmitted from the ground to the superstructure, it has been studied extensively. Different types of isolation bearings have been developed as effective strategies to protect infrastructure from seismic hazards [5-9]. For instance, steel-rubber isolators with rubber cores $[10,11]$, natural rubber bearings equipped with high toughness steel ring dampers [12], natural rubber bearings equipped with steel and shape memory alloys dampers [13], new rectangular rubber isolators with square rubber cores [14], and laminate rubber bearings (LRB) [15]; the above isolators are used for horizontal isolation.

Moreover, earthquakes are one of the most severe natural disasters that threaten the safety of nuclear power plants (NPPs). Although isolation technology has been widely deployed for industrial and civil buildings, bridges, and certain classes of infrastructure, 
the application of base isolation technology in NPPs is limited. Among all NPPs currently in commercial operation worldwide, only Koeberg in South Africa and Cruas in France have adopted base isolation technology, in which neoprene rubber bearings, including flat sliders in some installations, have been used as the horizontal base isolation $[16,17]$. The main reasons for the limited use of seismic isolation in NPPs, its development, and future research needs have been presented and identified $[18,19]$. Based on many new theories and techniques, the base isolation of NPPs in the horizontal direction has been widely studied. These conventional base isolation systems clearly show the benefits of seismic isolation in the horizontal direction. However, the vertical ground motions transmitted through the isolation system were either unchanged or even magnified [17,20-22].

It is known that the vertical seismic design of NPPs is as necessary and important as the horizontal directions, especially for the high intensity zone. If 3D seismic isolation is achieved, it would substantially enhance the economy and safety of NPPs. Hence, it is beneficial that a few isolation systems are invented to provide vertical isolation for NPPs. Various attempts have been made to provide enhanced protection against the vertical component of ground motion by using a complete three-dimensional (3D) seismic isolation system, or adding a vertical isolation system in combination with a horizontal isolation component or the vertical isolation of the main components associated to the horizontal base-isolation structure. Several vertical and 3D isolation systems which have potential application in modern nuclear facilities have been examined [23]. Devices such as the rolling seal-type air spring [24,25], hydraulic isolation systems [26], and coned disk springs [27-30] have been developed to provide isolation in the vertical direction. In order to achieve the effectiveness of 3D seismic isolation, they are proposed to be combined with a horizontal isolation component.

Although 3D seismic base isolation has not yet been applied to the engineering practice of NPPs, its development has become an attractive area of research. Since coned disk springs have high vertical bearing capacity and also low vertical stiffness, this method was selected to decouple the superstructure from the vertical component of ground motion. In this study, a new 3D combined isolation bearing (3D-CIB), composed of LRB coupled with the combined disk spring bearing (CDSB), is proposed. LRB is used as horizontal isolation component, with CDSB used as the vertical isolation component at the bottom. In this way, the combination of LRB and CDSB can achieve 3D seismic isolation. In contrast to the traditional bearings of coned disk springs with only one disk spring column [27-30], CDSB is composed of one main column and several auxiliary columns of coned disk springs. The advantage of CDSB is that the constitution can be flexibly adjusted according to the requirements of the bearing capacity and vertical stiffness. It should be noted that CDSB itself has a high damping ratio, i.e., $0.2-0.3$, due to the large number of coned disk springs stacked [31]. Since the equivalent damping ratio of CDSB is an important parameter affecting isolation performance, it is necessary to conduct a performance test to measure the vertical equivalent damping ratio for the practical application of CDSB. To investigate the influence of different vertical equivalent damping ratios of 3D-CIB on the seismic response and isolation effectiveness, four vertical equivalent damping ratios were assumed in this paper. Subsequently, a comparative study of the seismic response in terms of acceleration floor response spectra (FRS), peak acceleration, displacement response of the nuclear reactor building, and the dynamic response of 3D-CIB was carried out.

\section{Design of 3D Combined Isolation Bearing (3D-CIB)}

\subsection{Design Theory and Parameters of CDSB}

A typical plan and section view of the CDSB is illustrated in Figure 1. The main column of disk spring is located in the center, and the auxiliary columns are uniformly distributed on a large circle with a certain radius. It is worth noting that the number of auxiliary columns $m$ can be flexibly adjusted according to the bearing capacity and vertical stiffness requirements of the CDSB. The main and auxiliary columns are all equipped with central guide tubes, and the bottom of each central guide tube is rigidly connected 
to the bottom connection plate. The central guide tube is installed in the stack in order to prevent excessive side slip. The upper part of each main and auxiliary column is connected to a guide sleeve, which is integrated with the top connection plate. These components including the bottom connection plate, central guide tubes, guide sleeves, and top connection plate together ensure that the horizontal stiffness of the CDSB is sufficient.

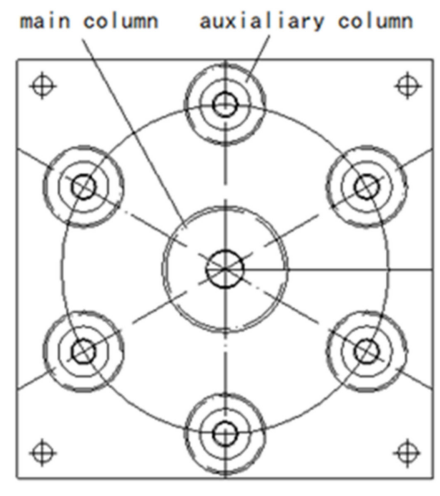

(a)

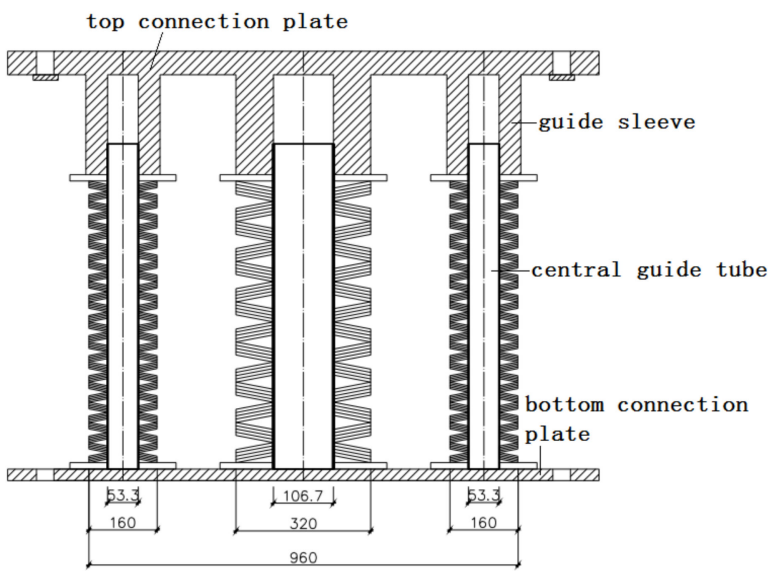

(b)

Figure 1. Typical plan and section view of the combined disk spring bearing (CDSB). (a) Plan view; (b) Section view.

The compound combination adopted for CDSB is achieved through stacking the coned disk springs of the same shape in parallel, and then by piling up this set more and more in several series. The main column was composed by stacking $n_{c}$ coned disk springs in parallel, and then $i_{\mathcal{c}}$ sets in series, which made up $n_{\mathcal{c}} \times i_{\mathcal{c}}$ disk springs in total. Similarly, each auxiliary column was composed of the stack of $n_{s}$ coned disk springs in parallel, and then $i_{s}$ sets in series. The characteristic parameters of a coned disk spring with bearing surface, including the outer diameter $(D)$, inner diameter $(d)$, thickness of the bearing surface $(t)$, and inner coned height $(h)$, are shown in Figure 2. Accordingly, for the main and auxiliary coned disk springs, the above parameters are denoted as $D_{c}, d_{c}, t_{c}, h_{c}$ and $D_{s}$, $d_{s}, t_{s}, h_{s}$, respectively.

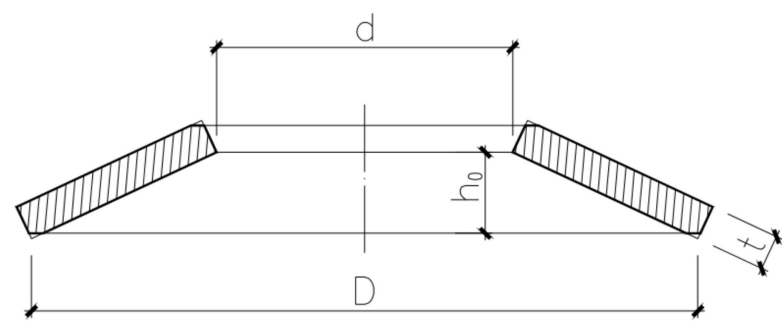

Figure 2. Structure size of single disk spring with bearing surface.

The principle of the coned disk spring was first presented by Almen and Laszlo [32] and then recommended for the existing national standard for coned disk springs [33]. Considering the main disk spring as an example, when the vertical load $F_{c}$ acts on the inner circumference of the coned disk spring, the deformation $f_{c}$ occurs:

$$
F_{C}=\frac{4 E}{1-\mu^{2}} \cdot \frac{t_{C}^{4}}{K_{1} D_{C}^{2}} \cdot K_{4}^{2} \frac{f_{C}}{t_{C}}\left[K_{4}^{2}\left(\frac{h_{C}}{t_{C}}-\frac{f_{C}}{t_{C}}\right)\left(\frac{h_{C}}{t_{C}}-\frac{f_{C}}{2 t_{C}}\right)+1\right]
$$

where $E$ is the elasticity modulus, $\mu$ is Poisson's ratio, and $K_{1}$ and $K_{4}$ are calculation coefficients. 
When the main disk spring is flattened, that is, $f_{c}=h_{c}$, Equation (1) yields the critical load of a coned disk spring $F_{C}$, as follows:

$$
F_{C c}=F_{\left(f_{C}=h_{C}\right)}=\frac{4 E}{1-\mu^{2}} \cdot \frac{t_{C}^{3} h_{C}}{K_{1} D_{C}^{2}} \cdot K_{4}^{2}
$$

The critical load of a single auxiliary disk spring $F_{S c}$ can be obtained in a similar manner. Finally, the critical load of the CDSB can be expressed as:

$$
F_{C D S B c}=F_{V C}+m F_{V S}=n_{C} F_{C c}+m n_{S} F_{S c}
$$

It is assumed that the weight of the superstructure borne by each CDSB is defined as $F$. Then, according to the deformation characteristics of the compound combination, the preloading initial deformation can be obtained as $f_{C D S B}=i_{c} f_{c}=i_{S} f_{s}$.

According to the stiffness definition of the coned disk spring, under the initial deformation of the main disk spring $f_{c}$, its vertical stiffness $K_{C}$ can be derived:

$$
K_{C}=\frac{d F_{C}}{d f_{C}}=\frac{4 E}{1-\mu^{2}} \cdot \frac{t_{C}^{3}}{K_{1} D_{C}^{2}} K_{4}^{2}\left\{K_{4}^{2}\left[\left(\frac{h_{C}}{t_{C}}\right)^{2}-3\left(\frac{h_{C}}{t_{C}}\right)\left(\frac{f_{C}}{t_{C}}\right)+\frac{3}{2}\left(\frac{f_{C}}{t_{C}}\right)^{2}\right]+1\right\}
$$

Further, the vertical stiffness of the main and auxiliary columns of the CDSB can be inferred as follows:

$$
\begin{aligned}
K_{V C} & =n_{C} K_{C} / i_{C} \\
K_{V S} & =n_{S} K_{S} / i_{S}
\end{aligned}
$$

Finally, the total vertical stiffness of the CDSB is obtained as follows:

$$
K_{V \text { CDSB }}=K_{V C}+m K_{V S}
$$

Owing to the large weight of the nuclear reactor building, a total of 245 bearings were set, and the average gravity load borne by each bearing was $2843 \mathrm{kN}$. Since many factors such as strength, critical load, and deformation should be considered in the design of the coned disk spring, after the trial calculation the geometrical parameters of the coned disk spring with the bearing surface were finally confirmed, as shown in Table 1.

Table 1. Geometrical parameters of the coned disk spring.

\begin{tabular}{ccccc}
\hline Type & $\begin{array}{c}\text { Outer } \\
\text { Diameter }(\boldsymbol{D})\end{array}$ & $\begin{array}{c}\text { Inner } \\
\text { Diameter }(\boldsymbol{d})\end{array}$ & $\begin{array}{c}\text { Thickness of } \\
\text { Bearing Surface }(\boldsymbol{t})\end{array}$ & $\begin{array}{c}\text { Inner Cone } \\
\text { Height }(\boldsymbol{h})\end{array}$ \\
\hline Main disk spring & 320 & 106.7 & 17.6 & 8.8 \\
\hline Auxiliary disk spring & 160 & 53.3 & 8.8 & 4.4 \\
\hline
\end{tabular}

(Unit: $\mathrm{mm}$ ).

According to Equation (2), the critical loads of the single main and auxiliary disk spring are $F_{C c}=623.1 \mathrm{kN}$ and $F_{S c}=155.8 \mathrm{kN}$, respectively. For the compound combination of the CDSB in this paper, $m=6, n_{c}=n_{S}=4, i_{s}=2 i_{c}=28$. According to Equation (3), the critical load of the CDSB is $F_{C D S B C}=6231.3 \mathrm{kN}$.

Based on the preloading initial displacement of the main and auxiliary disk spring, it can be obtained from Equation (4) that the vertical stiffness values of the single main and auxiliary coned disk spring are $K_{C}=7.238 \times 10^{7} \mathrm{~N} / \mathrm{m}$ and $K_{S}=1 / 2 K_{C}$, respectively. Finally, according to Equation (5) and Equation (6), the vertical stiffness of the CDSB can be obtained $\mathrm{K}_{\mathrm{VCDSB}}=5.170 \times 10^{7} \mathrm{~N} / \mathrm{m}$.

\subsection{Design Theory of $3 D-C I B$}

3D-CIB consists of a CDSB to provide vertical isolation, which is supported by a LRB to provide horizontal isolation. The CDSB and LRB are stacked in series using high-strength bolts, as illustrated in Figure 3. The LRB has small horizontal stiffness and high vertical 
stiffness, whereas the CDSB exhibits high horizontal stiffness, and its vertical stiffness is significantly lower than that of the LRB. Therefore, it can be inferred that the horizontal stiffness $\left(K_{H_{3 D-C I B}}\right)$ of the 3D-CIB only considers the horizontal stiffness of the LRB $\left(K_{H_{\mathrm{LRB}}}\right)$, and the vertical stiffness $\left(K_{V_{3 \mathrm{D}-\mathrm{CIB}}}\right)$ is calculated according to a series combination of LRB and CDSB. In summary, the horizontal and vertical stiffness of the 3D-CIB is as follows:

$$
\begin{aligned}
& K_{H} 3 \mathrm{D}-\mathrm{CIB}=K_{H} \mathrm{LRB} \\
& K_{V} 3 \mathrm{D}-\mathrm{CIB}=K_{V \text { LRB }} K_{V \text { CDSB }} /\left(K_{V \text { LRB }}+K_{V \text { CDSB }}\right)
\end{aligned}
$$

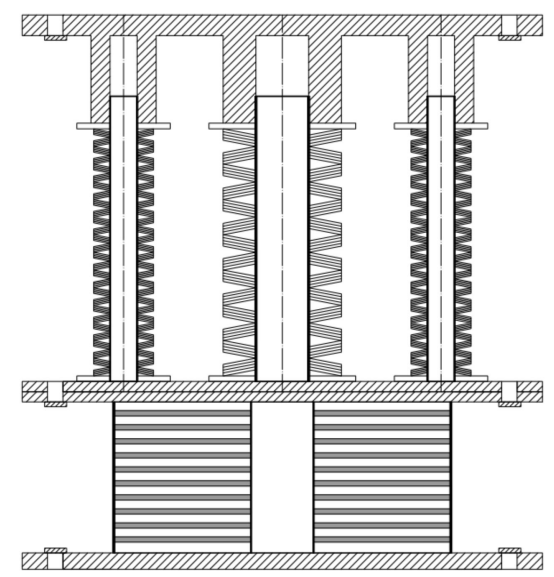

Figure 3. Section view of the 3D combined isolation bearing (3D-CIB).

In this study, the LRB with an additional lead core to enhance the energy dissipation capacity was used, with the vertical stiffness $K_{V_{\mathrm{LRB}}}=3.392 \times 10^{9} \mathrm{~N} / \mathrm{m}$, initial stiffness before yield $K_{u}=1.32 \times 10^{7} \quad \mathrm{~N} / \mathrm{m}$, stiffness after yield $K_{d}=1.2 \times 10^{6} \quad \mathrm{~N} / \mathrm{m}$, yield load $Q_{d}=113 \mathrm{kN}$, equivalent damping ratio $\zeta_{e q}=0.25$, and ultimate shear displacement $D_{u l t}=40 \mathrm{~cm}$. According to Equation (7), the vertical stiffness values of the 3D-CIB can be obtained $K_{V_{3 \mathrm{D}-\mathrm{CIB}}}=5.092 \times 10^{7} \mathrm{~N} / \mathrm{m}$.

\section{Basic Data for Numerical Analysis}

\subsection{D Base-Isolated Nuclear Reactor Building}

In this study, the nuclear reactor building includes three parts: raft foundation, containment, and internal structure. The outer diameter, height, and thickness of the containment were 51.2, 69.0, and $1.15 \mathrm{~m}$, respectively. The commercial finite element software ANSYS was employed to establish the 3D model, as shown in Figure 4. The raft foundation, with a thickness of 3.5 m (EL. 5.2-8.7 m), was meshed by the element type of Solid 185 . Containment was meshed by the element type of Shell 181, and the element sizes of the cylinder and dome were approximately $1.6 \mathrm{~m} \times 1.7 \mathrm{~m}$ and $1.6 \mathrm{~m} \times 1.2 \mathrm{~m}$, respectively. To simplify the model and reduce the calculation time, a lumped mass stick model of the internal structure was developed by the element type of Beam 188 and Mass 21. Generally, the properties of the lumped mass stick model were back-calculated from an analysis of the real 3D structure, and can represent the dynamic characteristics of the real 3D structure. The total weight of the nuclear reactor building was 70,966 tons. A total of 245 isolation bearings were uniformly distributed beneath the raft foundation, as shown in Figure 5. The element type of COMBIN40, in which both the bilinear strengthening model and the effects of viscous damping are considered, was adopted to simulate the horizontal behavior of 3D-CIB. COMBIN40 includes two spring constants $\left(K_{1}\right.$ and $\left.K_{2}\right)$, damping coefficient $(C)$, mass constant $(M)$, gap size $(G A P)$, and limiting sliding force (FSLIDE). The relationship among initial stiffness $K_{u}, K_{1}$, and $K_{2}$ is that $K_{u}=K_{1}+K_{2}$. Mass constant $(M)$ and gap size $(G A P)$ are set to zero for isolators. The element type of COMBIN14, whose real constants include the spring constant $(K)$ and damping coefficient $\left(C_{V}\right)$, was adopted to simulate the 
vertical characteristics of 3D-CIB. The geometry and mechanical models of COMBIN14 and COMBIN40 are shown in Figure 6. Thus, one element of COMBIN14 and two elements of COMBIN40 were used to simulate an isolation bearing in which one node of each element was shared with the bottom node of the raft foundation, and the other node was a fixed constraint (i.e., restraining degrees of freedom $(\mathrm{DoF})$ of translation along the three orthogonal directions) for the boundary condition.

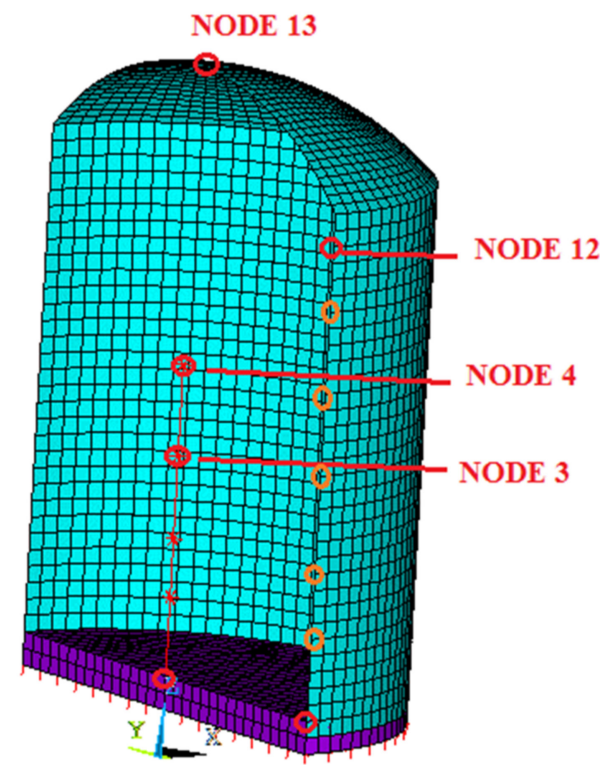

Figure 4. Finite element model of a nuclear reactor building.

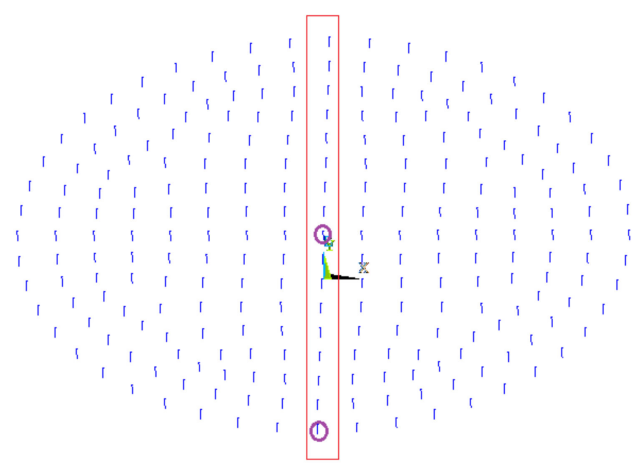

Figure 5. Layout of discrete 3D-CIBs beneath the raft foundation.

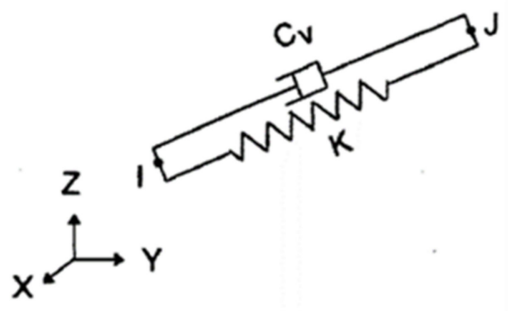

(a)

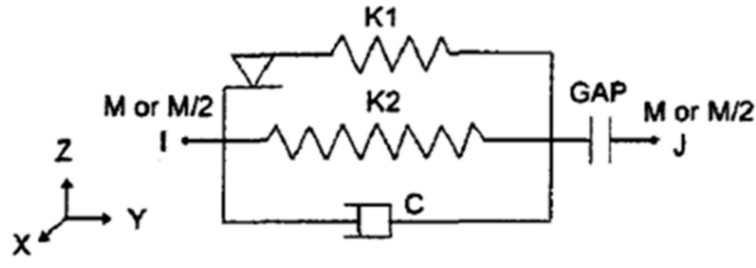

(b)

Figure 6. The geometry and mechanical model of the spring-damper element. (a) COMBIN14; (b) COMBIN40. 


\subsection{Input Ground Motion}

In this paper, the three translational components of the artificial acceleration time histories, plotted in Figure 7, are the input ground motions. The corresponding response spectra for a damping ratio of $5 \%$, plotted in Figure 8, are the design response spectra of the Regulatory Guide 1.60 [34]. The peak ground acceleration in both the horizontal and vertical directions is $2.943 \mathrm{~m} / \mathrm{s}^{2}$, i.e., $0.3 \mathrm{~g}\left(\mathrm{~g}=9.81 \mathrm{~m} / \mathrm{s}^{2}\right)$, the total duration and time step is $28 \mathrm{~s}$ and $0.01 \mathrm{~s}$, respectively. All three components were statistically independent of each other. Consequently, according to the Regulatory Guide 1.92 [35], the seismic response of the structure was directly obtained from the algebraic summation.

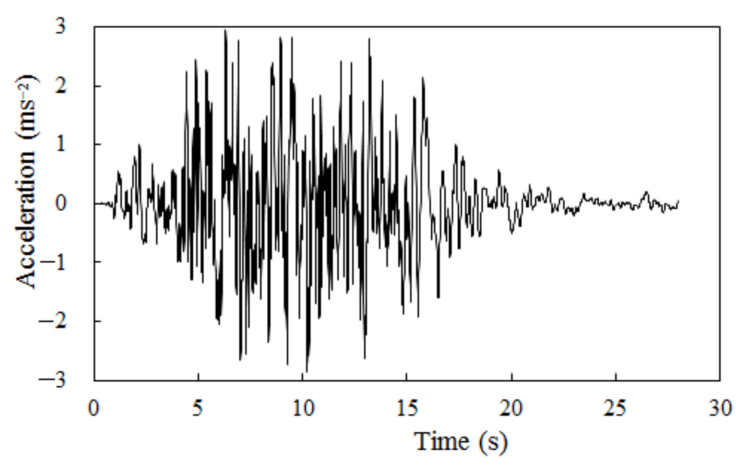

(a)

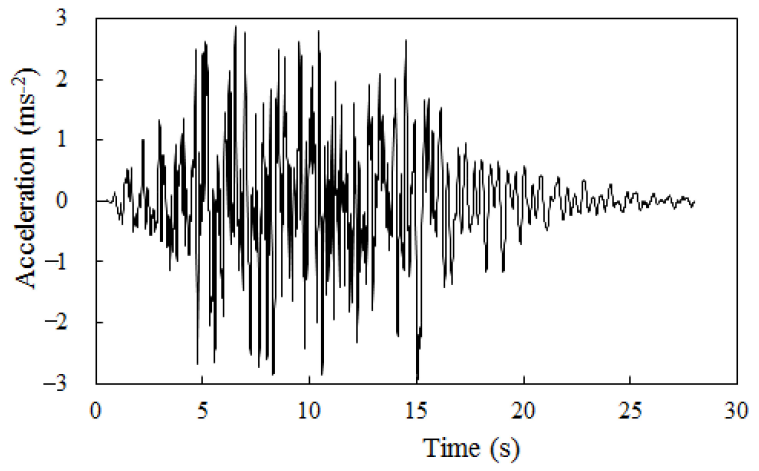

(b)

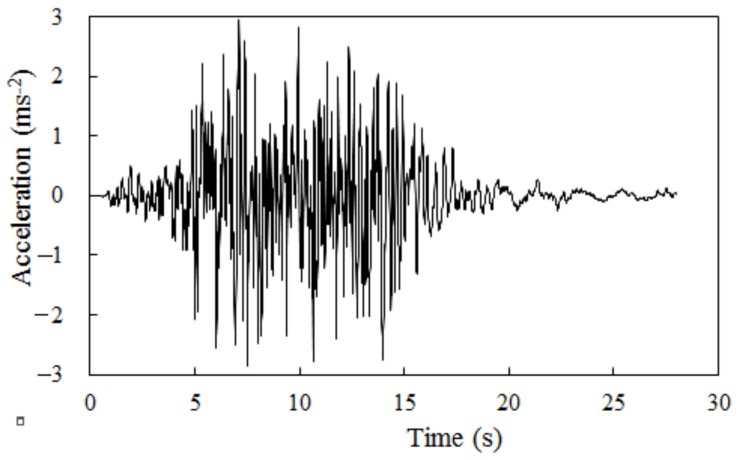

(c)

Figure 7. The acceleration time-histories of seismic motion. (a) In the horizontal direction $X$; (b) In the horizontal direction $Y$; (c) In the vertical direction $Z$.

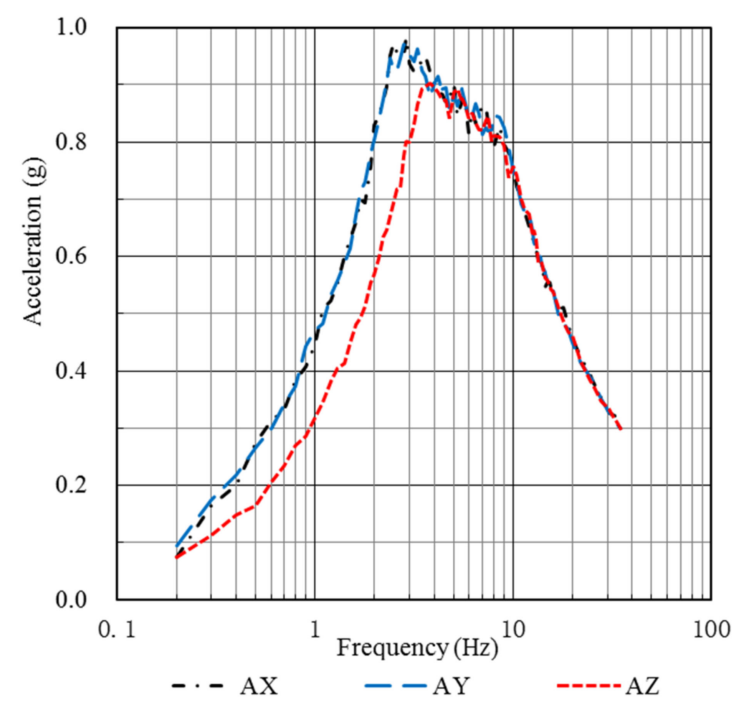

Figure 8. The acceleration response spectra of the input ground motion. 


\section{Results and Discussion}

Firstly, a modal analysis of both a non-isolated and 3D base-isolated nuclear reactor building was performed. Subsequently, to investigate the influence of different vertical equivalent damping ratios of $3 \mathrm{D}-\mathrm{CIB}$ on the seismic response and isolation effectiveness, four vertical equivalent damping ratios of 10,15, 20, and 25\% for 3D-CIB were assumed in this paper. Finally, the seismic isolation effectiveness of 3D-CIB with different vertical equivalent damping ratios was compared and discussed.

\subsection{Modal Analysis}

Firstly, the main frequencies and mode shapes that reflect the dynamic characteristics of the non-isolated and 3D base-isolated nuclear reactor building can be obtained. The main frequencies are provided in Table 2 . In this table, " $U_{X}, U_{Y}, U_{Z}$ " denote the DoFs of translation in the, $X, Y$, and $Z$ directions, respectively. "ROT $Z$ " denotes the DoF of torsion around the Z-axis. "FIXED" and "3D-CIB" denote the results calculated for the non-isolated and 3D base-isolated structure with 3D-CIB, respectively. As can be seen in Table 2, the main frequencies of the 3D isolated structure for the DoFs of both translation and torsion are significantly reduced compared to that of the non-isolated structure. The comparison of these frequencies confirms that the design objective is reached.

Table 2. Comparison of the natural frequencies of vibration.

\begin{tabular}{cccc}
\hline ORDER & MODE & 3D-CIB & FIXED \\
\hline 1 & $U_{X}$ & 0.705 & 4.541 \\
\hline 2 & $U_{Y}$ & 0.710 & 4.540 \\
\hline 3 & $R O T_{Z}$ & 1.086 & 9.455 \\
\hline 4 & $U_{Z}$ & 2.084 & 13.750 \\
\hline
\end{tabular}

(Unit: Hz).

\subsection{Comparison of Floor Response Spectra (FRS)}

The seismic demands for safety-related secondary mechanical, electrical, and piping systems in NPPs are generally using FRS. A comparative study of the FRS was focused on the representative nodes, including containment nodes located at the ring crane (NODE 12) and dome top (NODE 13), secondary top node (NODE 3), and top node (NODE 4) of the internal structure, as shown in Figure 4. It is noticed that the horizontal FRS for NODE 3 and NODE 4 of the internal structure is extracted only in the $X$ direction, owing to the structural symmetry in the horizontal plane. For brevity, the 5\% damped FRS for the horizontal and vertical directions are plotted in Figures 9 and 10, respectively. The legends of "FIXED" and "25\%" denote the results calculated for the non-isolated structure and 3D base-isolated structure of 3D-CIB with a vertical equivalent damping ratio of $25 \%$, respectively. Moreover, a comparison of the spectral acceleration peak value $\left(S_{\max }\right)$, reduction rate of $S_{\max }(\delta)$, and zero period acceleration (ZPA) of the horizontal and vertical FRS are summarized in Tables 3 and 4, respectively.

Table 3. Comparison of peak values and ZPA of the FRS in the horizontal direction.

\begin{tabular}{|c|c|c|c|c|c|c|c|c|c|c|c|c|}
\hline \multirow{2}{*}{ TYPE } & \multicolumn{3}{|c|}{ NODE12_X } & \multicolumn{3}{|c|}{ NODE12_Y } & \multicolumn{3}{|c|}{ NODE13_X } & \multicolumn{3}{|c|}{ NODE13_Y } \\
\hline & $S_{\max }(\mathrm{g})$ & $\delta$ & $Z P A(\mathrm{~g})$ & $S_{\max }(\mathrm{g})$ & $\delta$ & $Z P A(\mathrm{~g})$ & $S_{\max }(\mathrm{g})$ & $\delta$ & $Z P A(\mathrm{~g})$ & $S_{\max }(\mathrm{g})$ & $\delta$ & $Z P A(\mathrm{~g})$ \\
\hline $25 \%$ & 0.776 & $12.4 \%$ & 0.232 & 0.855 & $14.1 \%$ & 0.264 & 0.977 & $13.2 \%$ & 0.294 & 1.102 & $15.0 \%$ & 0.349 \\
\hline $20 \%$ & 0.809 & $8.7 \%$ & 0.245 & 0.896 & $10.0 \%$ & 0.272 & 1.022 & $9.2 \%$ & 0.305 & 1.160 & $10.6 \%$ & 0.361 \\
\hline $15 \%$ & 0.845 & $4.6 \%$ & 0.259 & 0.943 & $5.2 \%$ & 0.280 & 1.071 & $4.9 \%$ & 0.320 & 1.225 & $5.6 \%$ & 0.374 \\
\hline $10 \%$ & 0.886 & - & 0.275 & 0.995 & - & 0.290 & 1.126 & - & 0.340 & 1.297 & - & 0.389 \\
\hline FIXED & 4.624 & - & 0.871 & 4.928 & - & 0.963 & 5.896 & - & 1.171 & 5.955 & - & 1.179 \\
\hline
\end{tabular}


Table 4. Comparison of peak values and ZPA of the FRS in the vertical direction.

\begin{tabular}{|c|c|c|c|c|c|c|c|c|c|c|c|c|}
\hline \multirow{2}{*}{ TYPE } & \multicolumn{3}{|c|}{ NODE3 } & \multicolumn{3}{|c|}{ NODE4 } & \multicolumn{3}{|c|}{ NODE12 } & \multicolumn{3}{|c|}{ NODE13 } \\
\hline & $S_{\max }(\mathrm{g})$ & $\delta$ & $Z P A(\mathrm{~g})$ & $S_{\max }(\mathrm{g})$ & $\delta$ & $Z P A(\mathrm{~g})$ & $S_{\max }(\mathrm{g})$ & $\delta$ & $Z P A(\mathrm{~g})$ & $S_{\max }(\mathrm{g})$ & $\delta$ & $Z P A(\mathrm{~g})$ \\
\hline $25 \%$ & 1.219 & $42.2 \%$ & 0.330 & 1.220 & $42.2 \%$ & 0.331 & 1.460 & $40.3 \%$ & 0.410 & 1.289 & $42.5 \%$ & 0.359 \\
\hline $20 \%$ & 1.387 & $34.2 \%$ & 0.362 & 1.389 & $34.2 \%$ & 0.363 & 1.669 & $31.8 \%$ & 0.425 & 1.479 & $34.1 \%$ & 0.382 \\
\hline $15 \%$ & 1.664 & $21.1 \%$ & 0.399 & 1.666 & $21.1 \%$ & 0.400 & 1.970 & $19.5 \%$ & 0.441 & 1.772 & $21.0 \%$ & 0.420 \\
\hline $10 \%$ & 2.109 & - & 0.460 & 2.111 & - & 0.460 & 2.448 & - & 0.509 & 2.243 & - & 0.479 \\
\hline FIXED & 2.444 & - & 0.552 & 2.539 & - & 0.570 & 2.426 & - & 0.647 & 6.776 & - & 1.329 \\
\hline
\end{tabular}

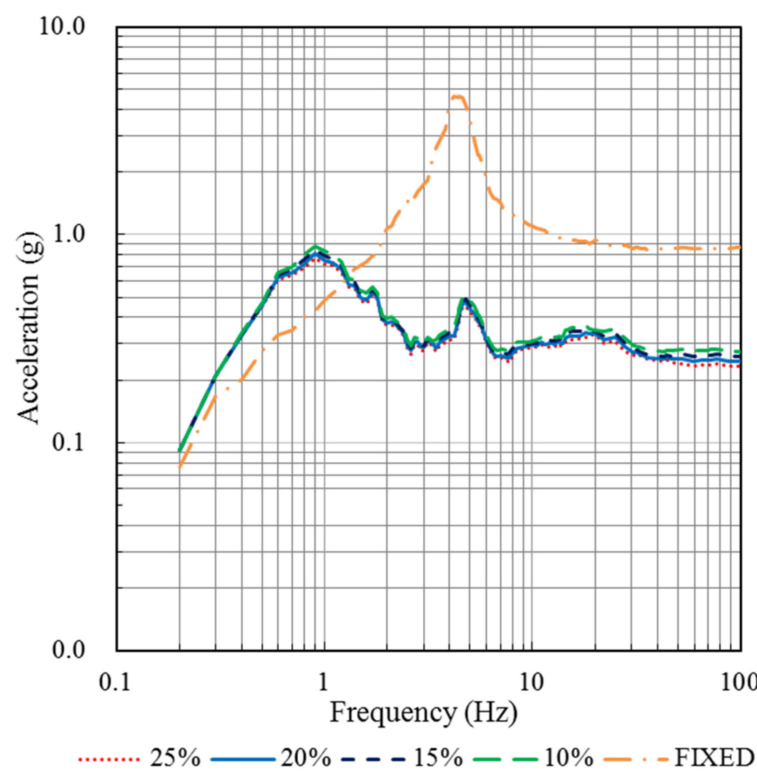

(a)

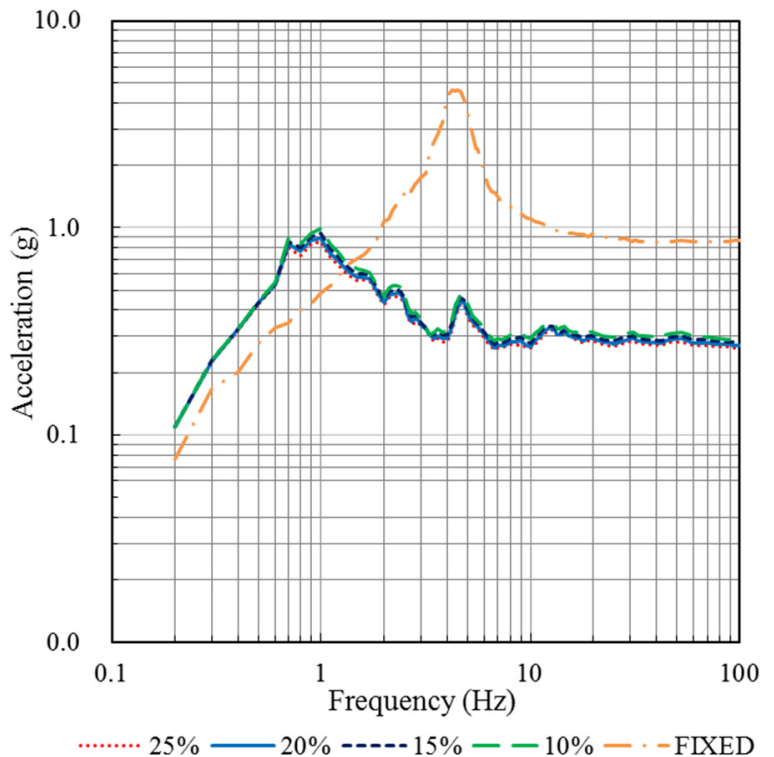

(c)

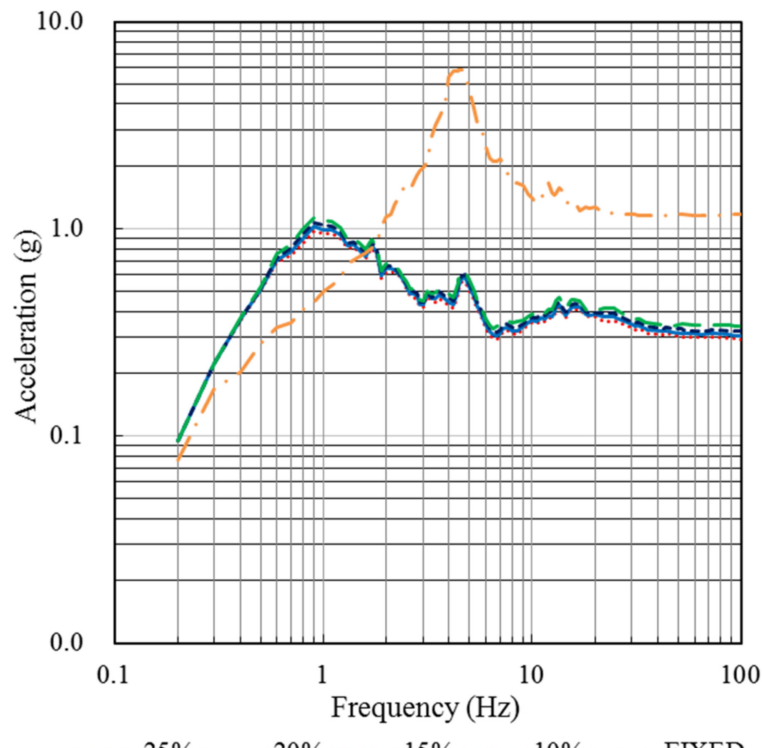

(b)

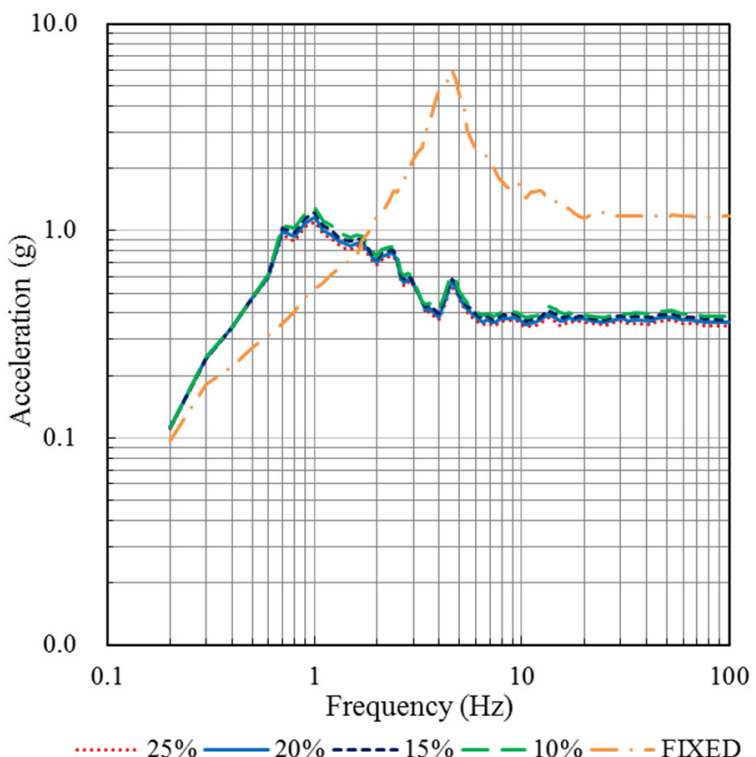

(d)

Figure 9. Cont. 


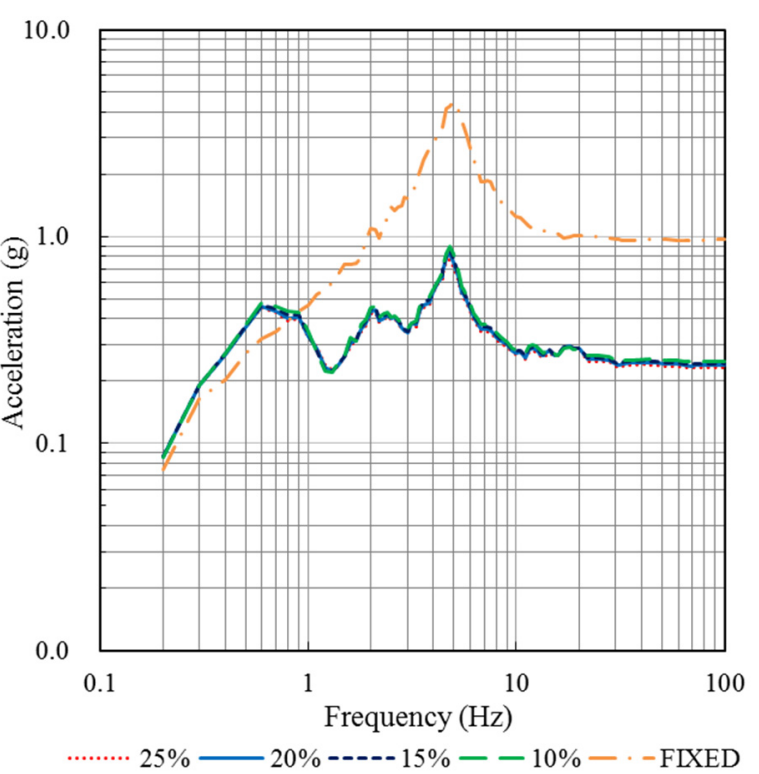

(e)

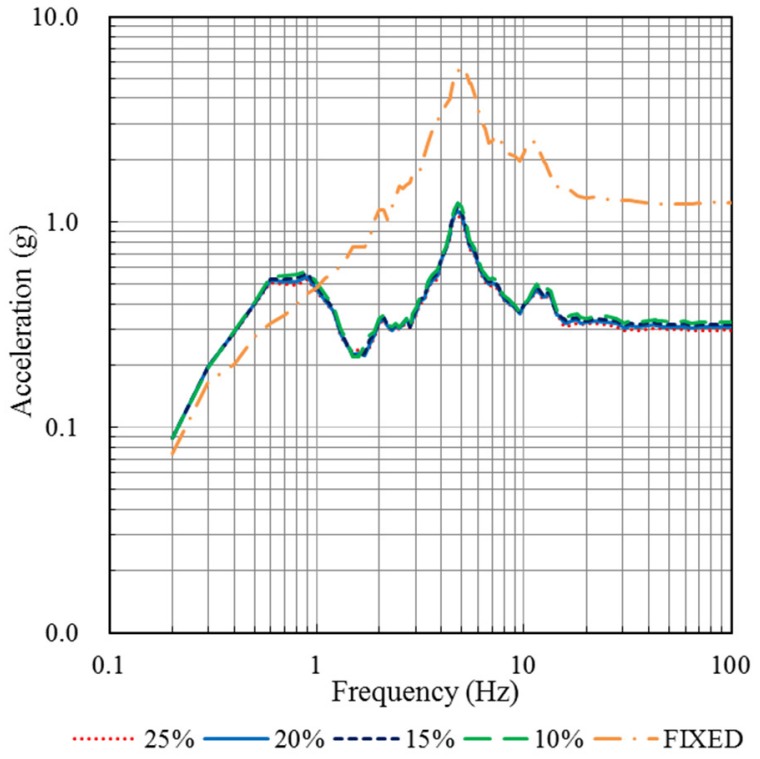

(f)

Figure 9. Comparison of the FRS of containment and internal structures in the horizontal direction. (a) NODE 12_X; (b) NODE 13_X; (c) NODE 12_Y; (d) NODE 13_Y; (e) NODE 3_X; (f) NODE 4_X.

\subsubsection{Analysis of FRS in the Horizontal Direction}

It can be observed from Figure 9 that there are no apparent differences among the spectral shapes and values of the 3D isolated structures with different vertical equivalent damping ratios, and the first peak states all occurred near the horizontal isolation frequency. Additionally, the spectral values in high-frequency range (i.e., above 1.0-2.0 Hz) are significantly reduced, compared to those of the non-isolated structures. Overall, the spectral peak values and ZPA slightly increased with a decrease of vertical equivalent damping ratio. Especially for containment nodes, it can be seen from Table 3 that the spectral peak values calculated by 15,20 , and $25 \%$ of vertical equivalent damping ratios are reduced by approximately 5,10 , and $15 \%$ respectively, compared with the corresponding results of the damping ratio $10 \%$. For internal structural nodes, the spectral peak values and ZPA calculated by different equivalent damping ratios are almost the same. In summary, it can be concluded that the horizontal FRS was slightly influenced by the vertical equivalent damping ratio of $3 \mathrm{D}-\mathrm{CIB}$.

\subsubsection{Analysis of the FRS in the Vertical Direction}

As shown in Figure 10, the spectral shapes calculated by different vertical equivalent damping ratios are similar, and all of them have peak values at $2.2 \mathrm{~Hz}$. Furthermore, the peak values and the spectral values to the right of spectral peak increased obviously with a decrease in the vertical equivalent damping ratio. As summarized in Table 4, the spectral peak values calculated by the vertical equivalent damping ratios of 15,20 , and $25 \%$ are approximately 20,35, and $40 \%$ lower than the corresponding results of the damping ratio of $10 \%$. Hence, it can be concluded that the increase of the vertical equivalent damping ratio has a significant effect on reducing the vertical FRS.

In addition, the spectral values near the peak frequency and to the left of the spectral peak are significantly magnified in comparison to those of the non-isolated structure. In contrast, the spectral values of the frequency range greater than approximately $3.5 \mathrm{~Hz}$ are obviously reduced. 


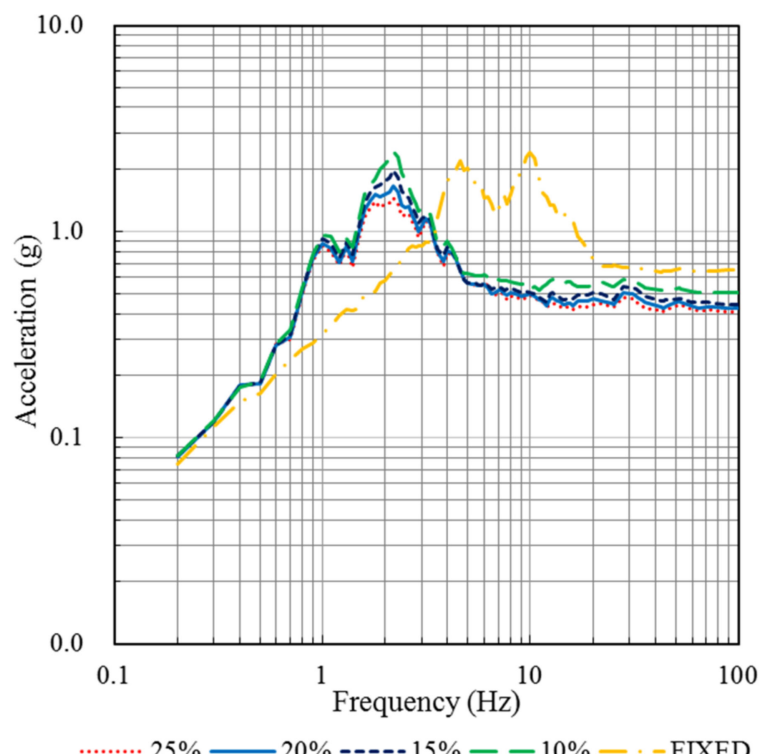

(a)

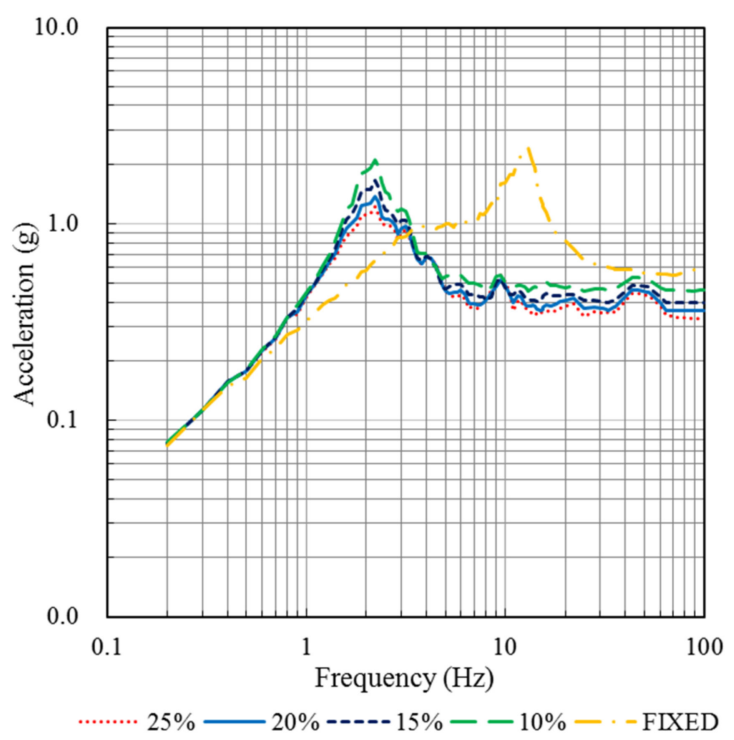

(c)

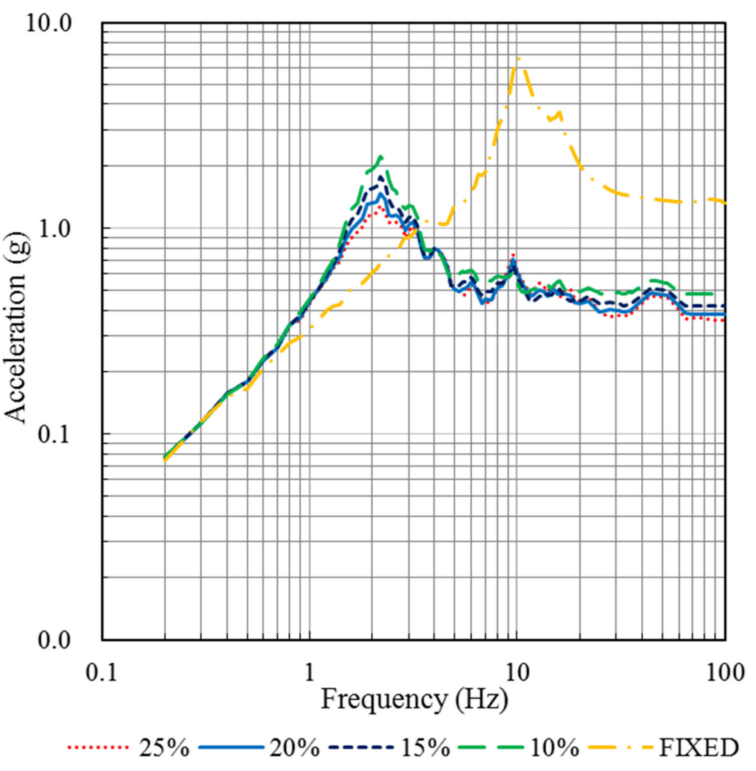

(b)

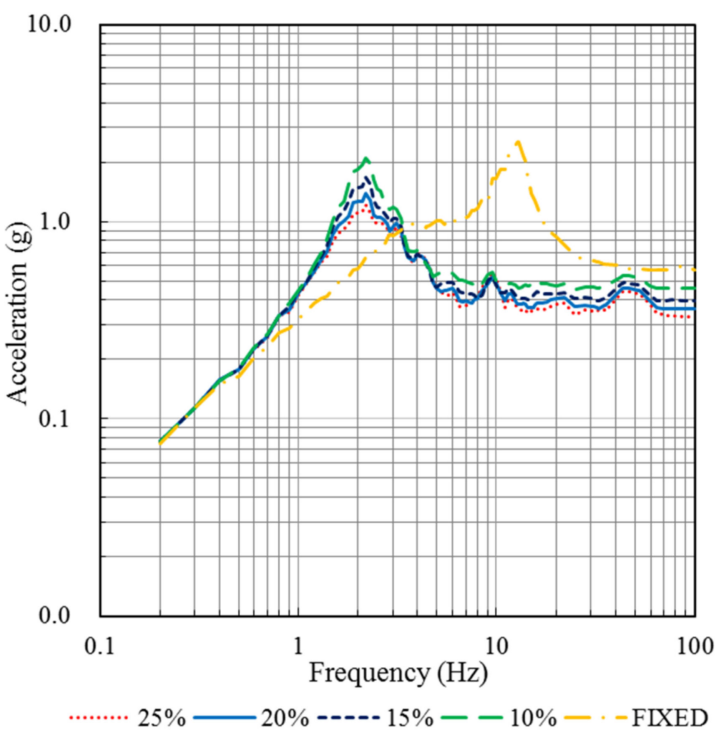

(d)

Figure 10. Comparison of the FRS of containment and internal structures in the vertical direction. (a) NODE 12; (b) NODE 13; (c) NODE 3; (d) NODE 4.

\subsection{Comparison of Peak Acceleration Response}

In this section, the acceleration response of the nodes at different elevations of the containment and internal structure, as shown in Figure 4, were extracted. The absolute peak accelerations versus the height of containment and internal structure are plotted in Figures 11 and 12, respectively. In general, it appeared that both the horizontal and vertical peak accelerations of the 3D isolated structure did not vary much with height, whereas they were obviously amplified along the height of the non-isolated structure. 


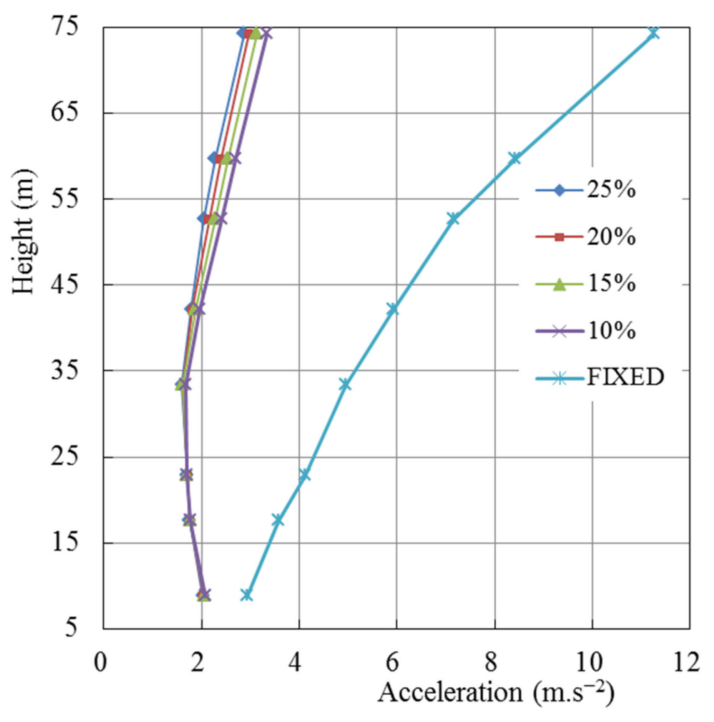

(a)

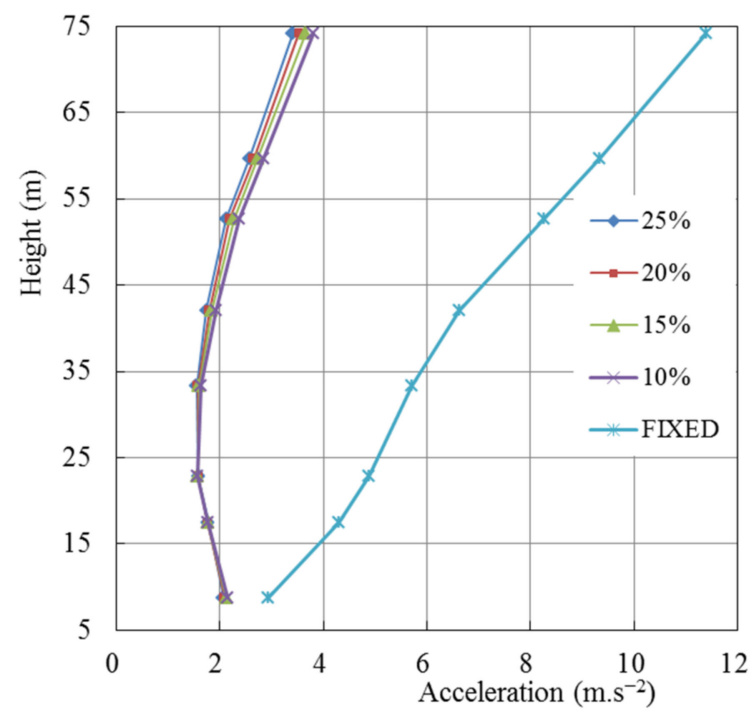

(b)

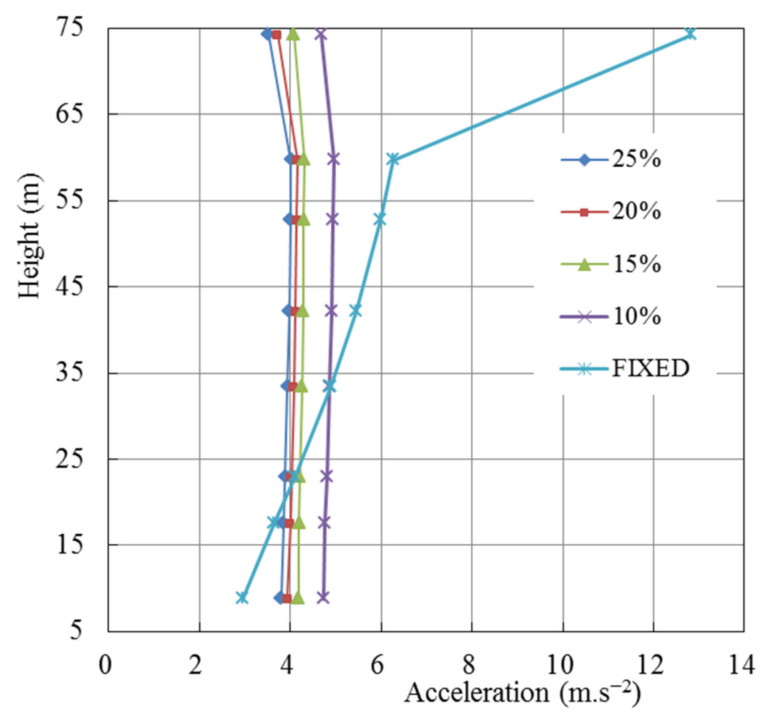

(c)

Figure 11. Comparison of the peak acceleration response of the containment. (a) In the horizontal direction $X$; (b) In the horizontal direction $Y$; (c) In the vertical direction $Z$.

As shown in Figures 11 and 12, the peak values of the horizontal acceleration response calculated by different vertical equivalent damping ratios of 3D-CIB are equivalent in the middle and lower parts of the containment and internal structures, while the peak values slightly increased with the decrease of the equivalent damping ratio in the upper structure. Take the dome top node for example, compared with the vertical equivalent damping ratio of $10 \%$, the calculated values of 15,20 , and $25 \%$ are reduced by $5.9,10.5$, and $13.8 \%$, respectively. For the internal structure, the peak value of the Y-direction is little affected by the vertical equivalent damping ratio from the bottom to the top.

In the vertical direction, it is evident that the peak vertical acceleration increased with a decrease in the vertical equivalent damping ratios of 3D-CIB. For the top nodes of containment and internal structure, compared to the non-isolated structure, the substantial reduction ratios calculated by the vertical equivalent damping ratios of $10,15,20$, and $25 \%$ were $63.5,68.2,71.0$, and $72.6 \%$, and 22.2, 28.9, 35.7, and $41.2 \%$, respectively. Moreover, compared with the peak acceleration of the vertical equivalent damping ratio of $25 \%$, the corresponding results of 10,15 , and $20 \%$ are increased by $33.1,16.1$, and $5.9 \%$, and 39.2 , 
20.9 , and $9.4 \%$, respectively. For the sub top node of the containment, compared to the non-isolated structure, the substantial reduction ratios calculated by the vertical equivalent damping ratios of $10,15,20$, and $25 \%$ were $21.0,31.4,33.8$, and $36.0 \%$, respectively. Compared with the vertical equivalent damping ratio of $25 \%$, the calculated values of 10,15 , and $20 \%$ are increased by $24.5,7.3$, and $3.5 \%$, respectively. From the above comparison, it can be inferred that the difference of peak accelerations calculated by the damping ratio of 20 and $25 \%$ is within $10 \%$.

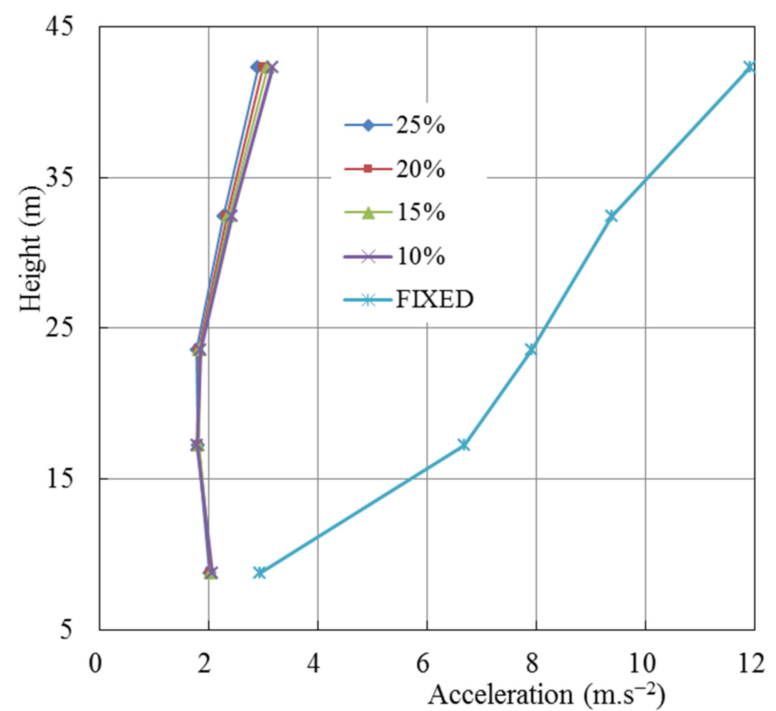

(a)

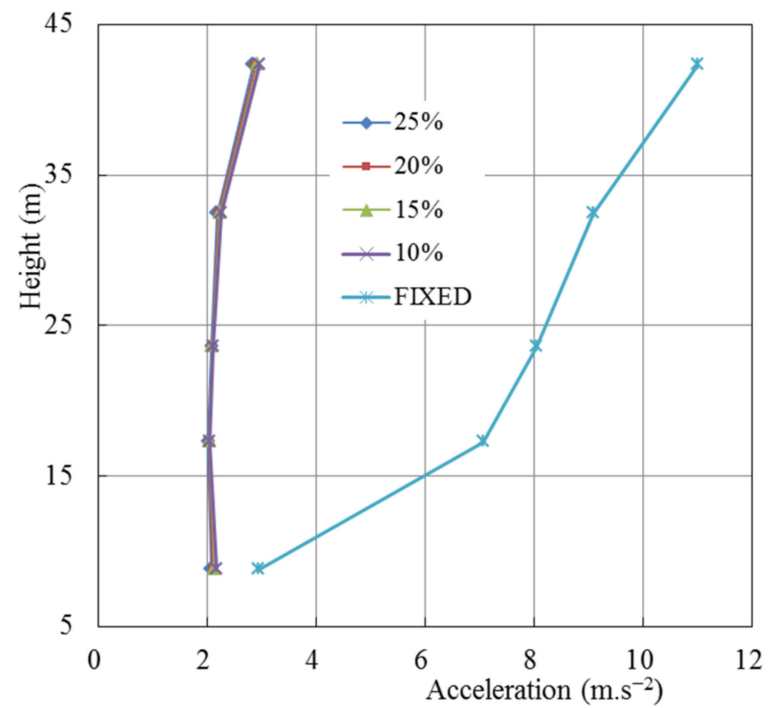

(b)

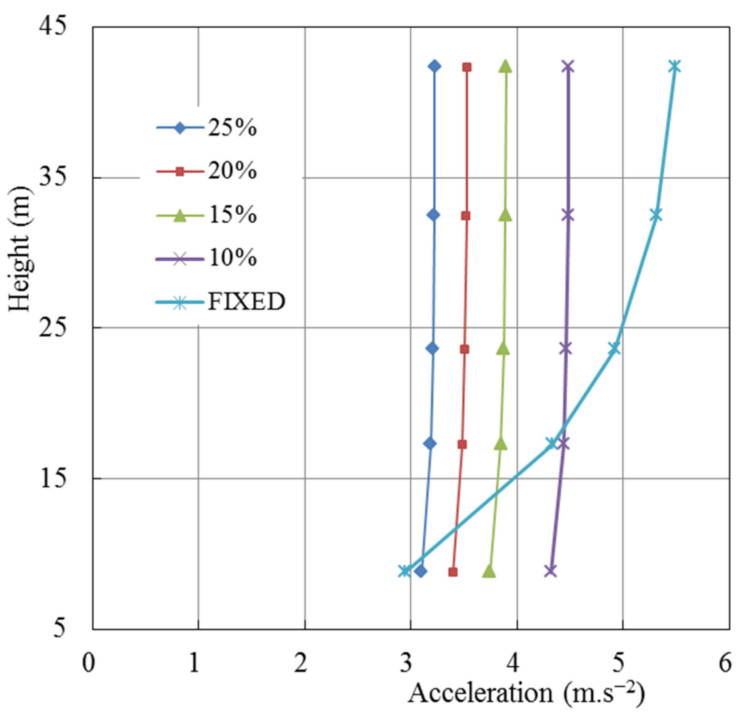

(c)

Figure 12. Comparison of the peak acceleration response of the internal structure. (a) In the horizontal direction $X$; (b) In the horizontal direction $Y$; (c) In the vertical direction $Z$.

\subsection{Comparison of Relative Displacement Response}

The displacement response of the 3D isolated and non-isolated structures relative to the ground is presented in this section. Note that all the displacement responses were obtained by considering the action of a gravity superimposed earthquake. The peak displacements of the nodes at different elevations of the containment and internal structures are plotted in Figures 13 and 14, respectively. The legends "25\%+" and " $25 \%$-" denote the displacement response along the coordinate axis in the positive and negative directions, 
which is calculated by 3D isolated structure of 3D-CIB with a vertical equivalent damping ratio of $25 \%$.

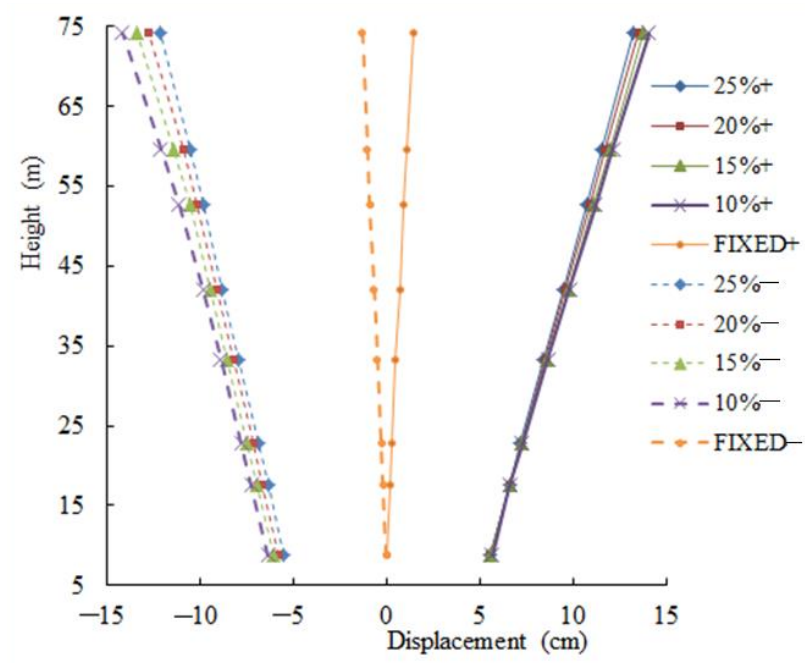

(a)

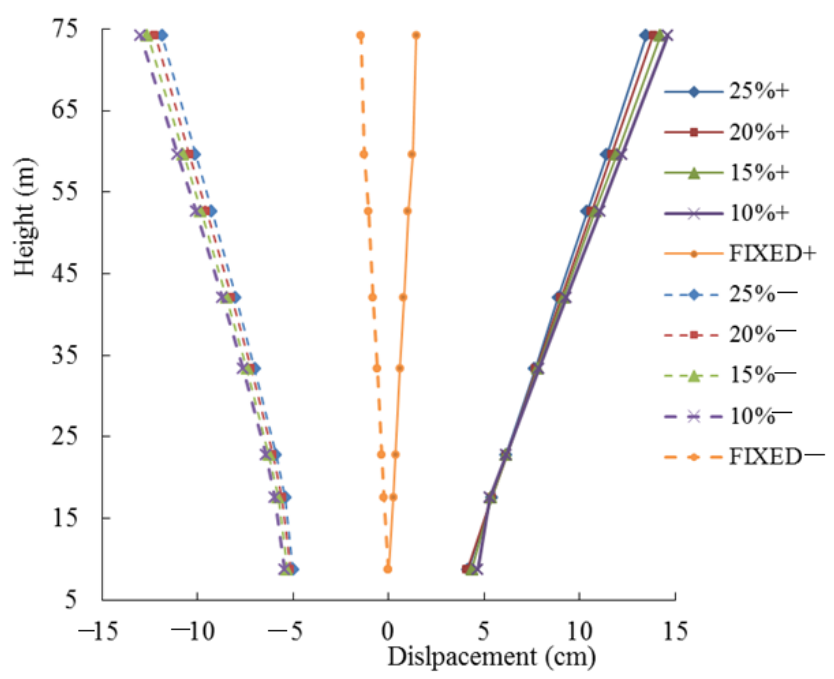

(b)

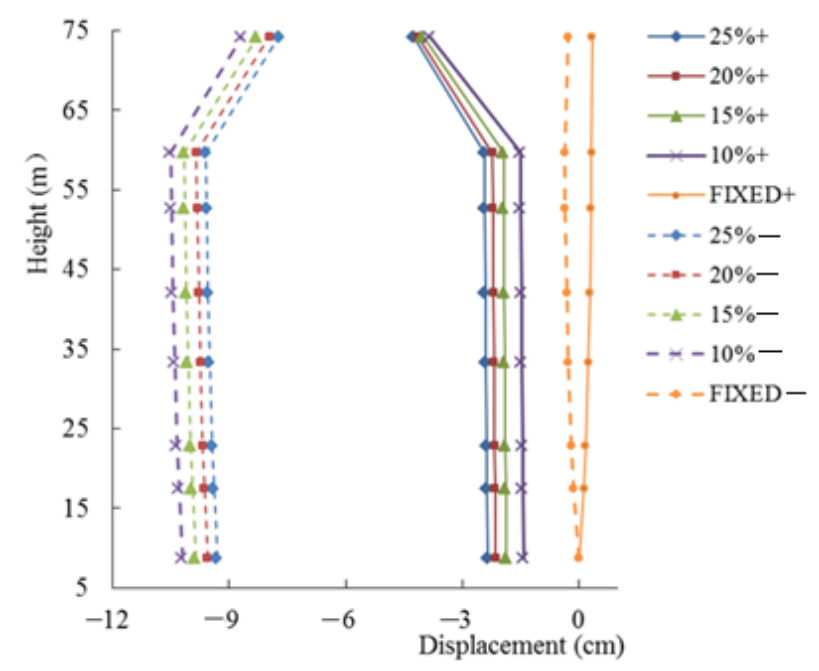

(c)

Figure 13. Comparison of the peak displacement response of the containment. (a) In the horizontal direction $X$; (b) In the horizontal direction $Y$; (c) In the vertical direction $Z$.

It is observed that the horizontal peak displacement along the positive direction of the middle and upper part of containment and internal structure, calculated by different vertical equivalent damping ratios of isolation bearings, is slightly different, increasing slightly with the decrease of damping ratio. However, the horizontal peak displacement of containment and internal structure along the negative direction increases with a decrease in the vertical equivalent damping ratio. For the dome top node, the peak horizontal displacement of the dome top in the negative direction of the $X$-axis for 10,15, 20, and $25 \%$, as shown in Figure 13a, was 14.15, 13.40, 12.72, and $12.10 \mathrm{~cm}$, respectively. Compared with the vertical equivalent damping ratio of $25 \%$, the peak values calculated by 20,15 , and $10 \%$ are increased by $5.1,10.8$, and $14.5 \%$, respectively. In addition, it is clear that the peak horizontal displacement of the 3D isolated reactor building is undergoing some amplification along the height due to rocking effect. For the containment, the rocking ratio (i.e., the horizontal displacement of the dome top relative to the raft foundation divided 
by the height of dome top) for $10,15,20$, and $25 \%$, was $1 / 837,1 / 891,1 / 943$, and $1 / 997$, respectively. Thus, compared with the vertical equivalent damping ratio of $25 \%$, the rocking ratios calculated by 10,15 , and $20 \%$ are increased by $19.1,11.9$, and $5.7 \%$, respectively.

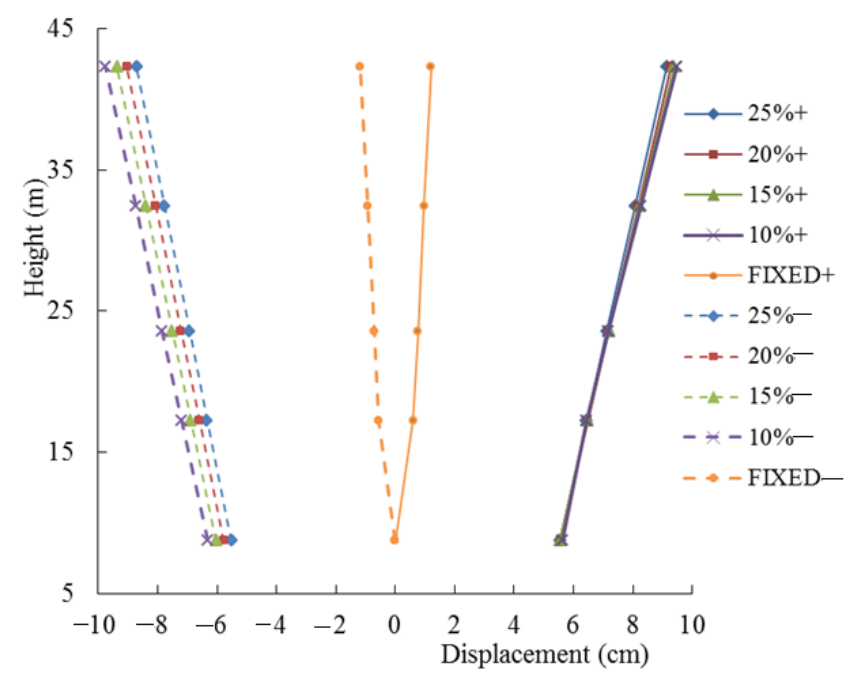

(a)

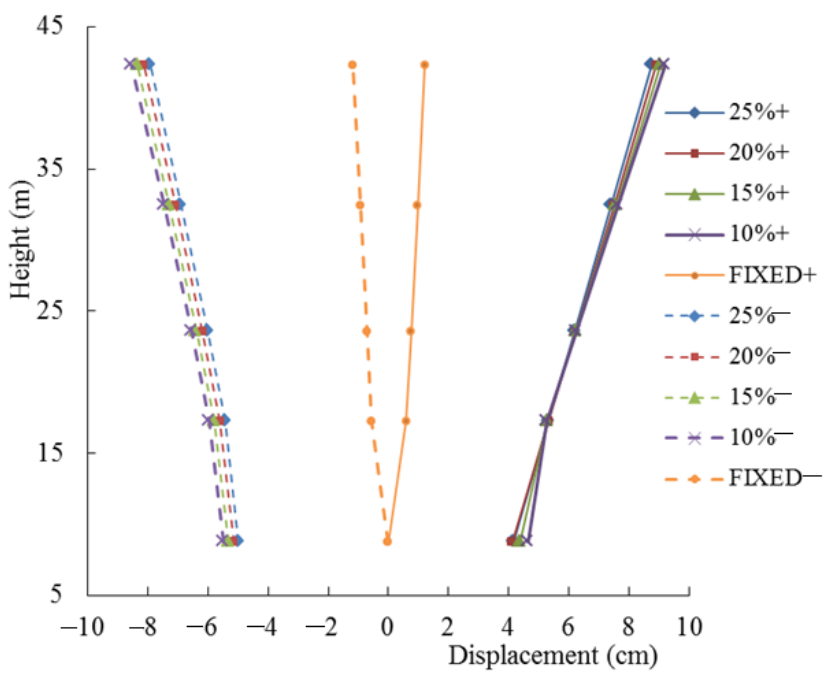

(b)

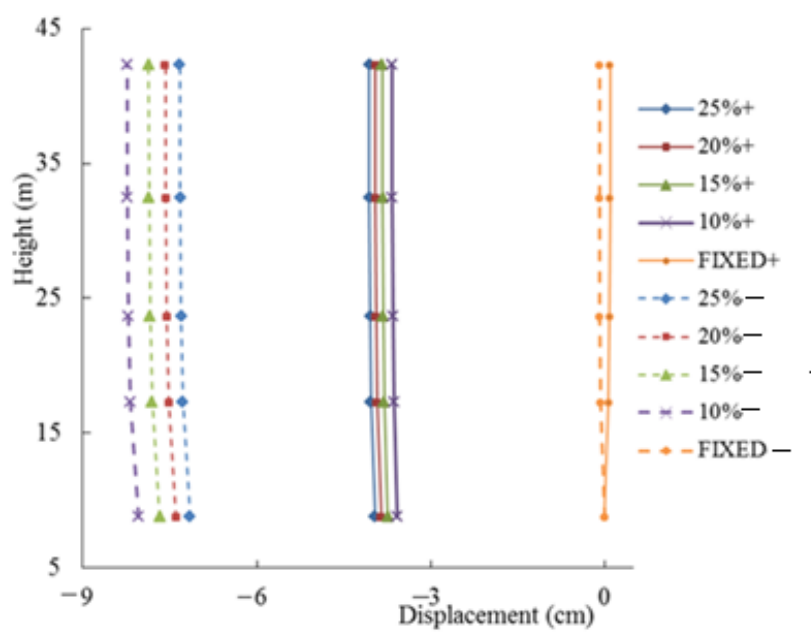

(c)

Figure 14. Comparison of the peak displacement response of the internal structure (a) In the horizontal direction $X$; (b) In the horizontal direction $Y$; (c) In the vertical direction $Z$.

As shown in Figures $13 \mathrm{c}$ and 14c, for the 3D isolated structure, the peak vertical displacement along the positive direction of the Z-axis is less than zero. Under earthquake action, the vertical vibration displacement calculated by different vertical equivalent damping ratios increased with the decrease of damping ratio. The vertical displacement vibration amplitudes of nodes at the top edge and center of the raft foundation as shown in Figure 5, calculated by vertical equivalent damping ratios of $10,15,20$, and 25\%, are 8.77, 8.00, 7.41, and $6.97 \mathrm{~cm}$, and 4.47, 3.94, 3.53, and $3.19 \mathrm{~cm}$, respectively. Consequently, compared with the vertical equivalent damping ratio of $25 \%$, the displacement amplitude calculated by 10 , 15 , and $20 \%$ are increased by $25.7,14.7$, and $6.3 \%$, and $39.9,23.3$, and $10.7 \%$, respectively. 


\subsection{Dynamic Response of 3D-CIB}

\subsubsection{Hysteretic Response of 3D-CIB}

As there are 245 bearings in the model, it is unfeasible to illustrate the response results of all the isolators. Therefore, the response of the center 3D-CIB is discussed in this section. For the 3D-CIB with different vertical equivalent damping ratios, its shape of hysteretic curves of shear and axial force-displacement response is similar, so the hysteretic shear and axial force-displacement response for the central 3D-CIB with damping ratio of $20 \%$ is shown in Figure 15. It can be seen that the hysteretic shape in the horizontal direction is different from the idealized hysteresis behavior of the bilinear mechanical model of LRB, due to the coupling effect of LRB and CDSB. For the axial force-displacement response, the hysteretic behavior performed ellipse, because the vertical stiffness of 3D-CIB is linear.

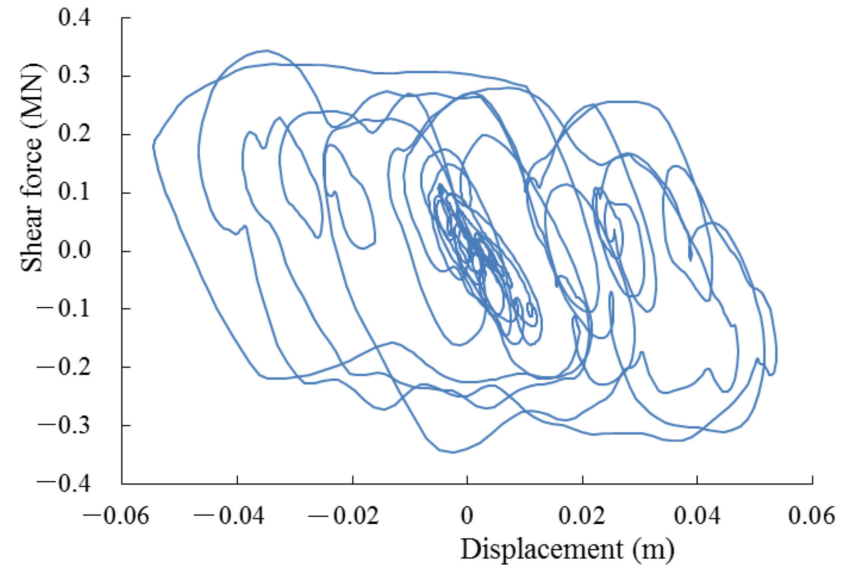

(a)

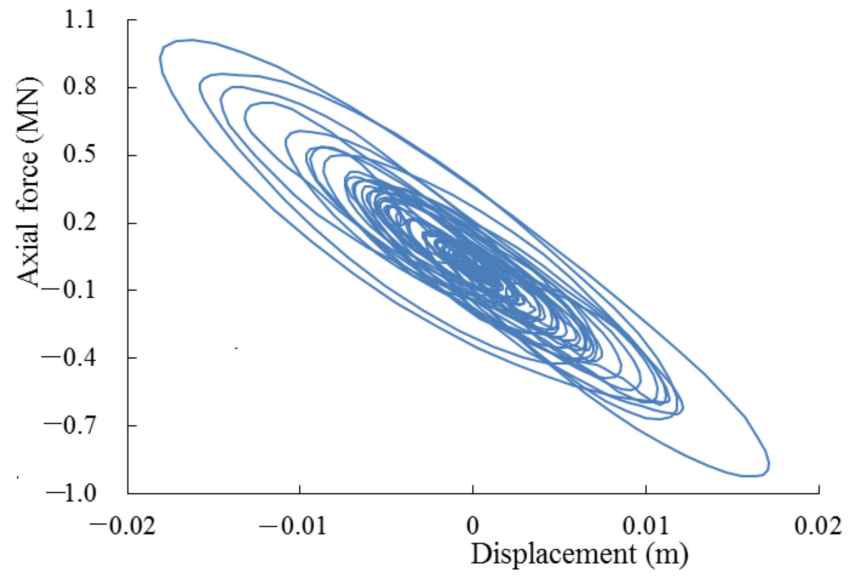

(b)

Figure 15. Hysteretic shear and axial force-displacement response of central 3D-CIB. (a) In the horizontal direction X; (b) In the vertical direction $Z$.

\subsubsection{Vertical Displacement Response of 3D-CIB}

A total of 17 bearings were arranged along the Y-axis beneath the raft foundation, as shown in Figure 5. The peak vertical displacements of 3D-CIB with different vertical equivalent damping ratios are shown in Figure 16. It is evident that the peak vertical displacements are all less than zero, which means that they are all in a compressed state under the action of the gravity superimposed earthquake. The peak vertical displacement along the negative direction and the displacement vibration amplitude of bearings with different vertical damping ratio increased with the decrease of equivalent damping ratios. Furthermore, the vertical displacement amplitude of the 3D-CIB near the edge was larger than that near the center, and the smaller the vertical damping ratio was, the more obvious the amplification effect. It was demonstrated that the rocking effect of the raft foundation occurred during the earthquake.

Figure 17 presents a comparison of the vertical displacement time histories of the center and edge bearings, as shown in Figure 5. Under the action of gravity, the initial displacements of the 3D-CIB at the center and edge are -5.56 and $-5.65 \mathrm{~cm}$, respectively. Then, under the gravity superposition earthquake action, the peak vertical displacements of the bearings with vertical equivalent damping ratios of $25,20,15$, and $10 \%$ are $-7.13,-7.37$, -7.66 , and $-8.02 \mathrm{~cm}$, and $-9.26,-9.51,-9.81$, and $-10.14 \mathrm{~cm}$, respectively. Compared with the peak vertical displacement of the bearing with a damping ratio of $25 \%$, the corresponding results of 10,15 , and $20 \%$ are increased by $12.4,7.3$, and $3.3 \%$, and $9.5,5.9$, and $2.6 \%$, respectively. Further, the deformation of the single main coned disk spring of the center and edge 3D-CIB with vertical equivalent damping ratios of $25,20,15$, and $10 \%$ was $5.10,5.27,5.47$, and $5.73 \mathrm{~mm}$, and $6.61,6.79,7.01$, and $7.25 \mathrm{~mm}$, corresponding to $0.58 h_{C}$, $0.60 h_{C}, 0.62 h_{C}, 0.65 h_{C}$, and $0.75 h_{C}, 0.77 h_{C}, 0.80 h_{C}$, and $0.82 h_{C}$, respectively. It is worth 
noting that the above deformation of the single main coned disk located at the center and edge was for all scenarios all less than $h_{C}$.

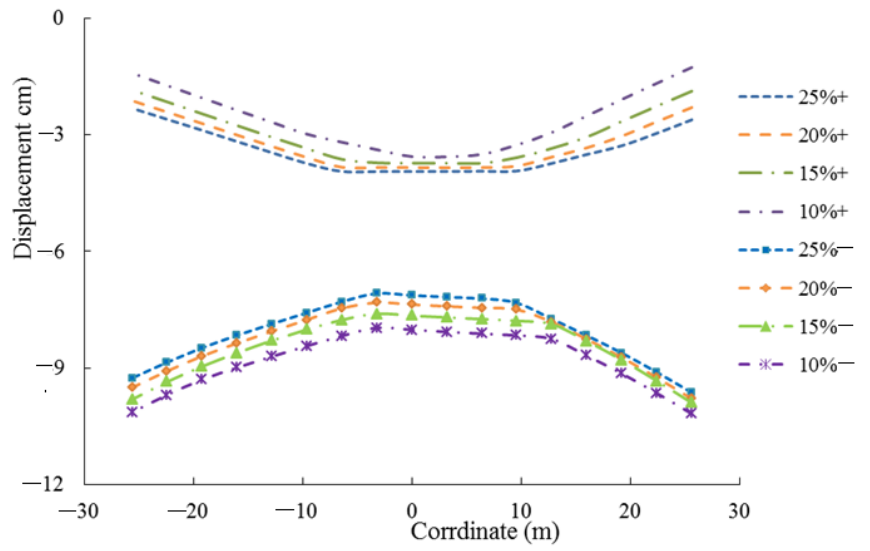

Figure 16. Comparison of the peak vertical displacement response of the 3D-CIBs.

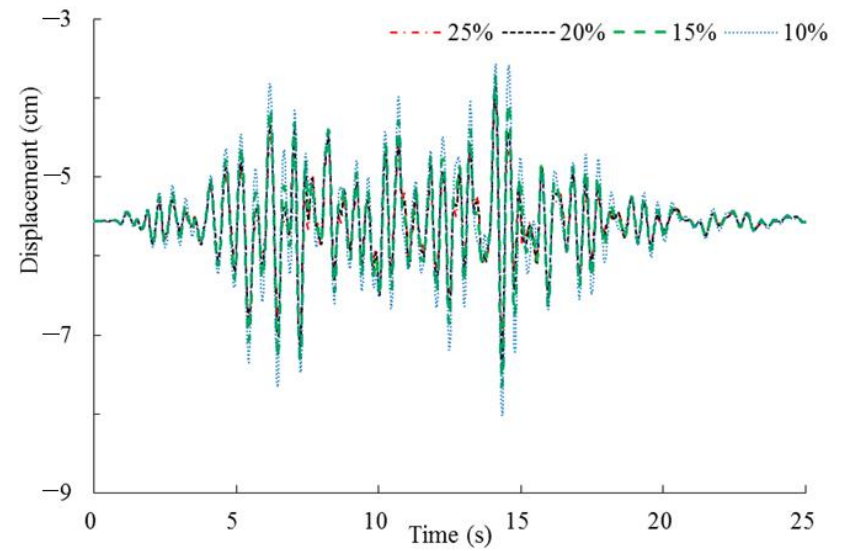

(a)

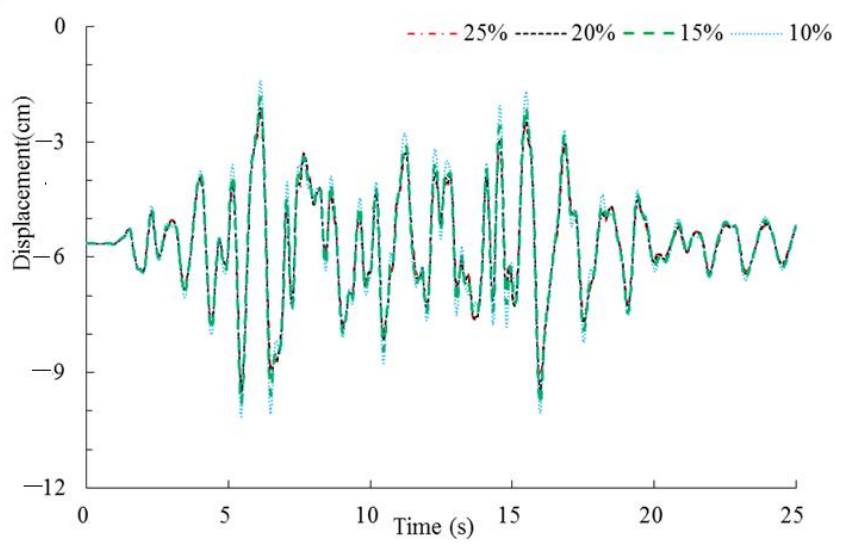

(b)

Figure 17. Comparison of the vertical relative displacement response of the center and edge 3D-CIBs. (a) At center; (b) At edge.

\subsubsection{Comparison of the Axial Force of 3D-CIB}

Under the action of the gravity superimposed earthquake, the peak axial forces of the bearings along the $Y$-axis are extracted as shown in Figure 18, in which the legend "3D-CIB-G" denotes the initial axial force of the bearings under the gravity action of the superstructure. It should be noted that the axial force of the 3D-CIB is positive in compression and negative in tension. As plotted in Figure 18, the initial axial forces of the bearings are uniform. Additionally, it is clear that the axial forces of bearings are all greater than zero, which means that they are all in compression, without the potential uplift. When the earthquake vibrated downward, the peak axial force of bearings decreased with the increase of the vertical equivalent damping ratio. In addition, the vertical force of the isolation bearing near the edge is obviously larger than that at the center. Taking the two side edge bearings along the positive and negative direction as an example, the peak axial force of bearings with damping ratios of $25,20,15$, and $10 \%$ is $4.953,5.021,5.063$, and $5.200 \times 10^{6} \mathrm{~N}$, and $4.838,4.921,5.040$, and $5.189 \times 10^{6} \mathrm{~N}$, and all less than the critical load $F_{C D S B}=6231.3 \mathrm{kN}$. Moreover, compared with the damping ratio of $25 \%$, the peak axial force of bearings of 10,15 , and $20 \%$ are reduced by $5.0,2.2$, and $1.4 \%$, and $7.2,2.4$, and $1.7 \%$, 
respectively. To sum up, the above results illustrated that the vertical equivalent damping ratio of 3D-CIB had a slight effect on axial force.

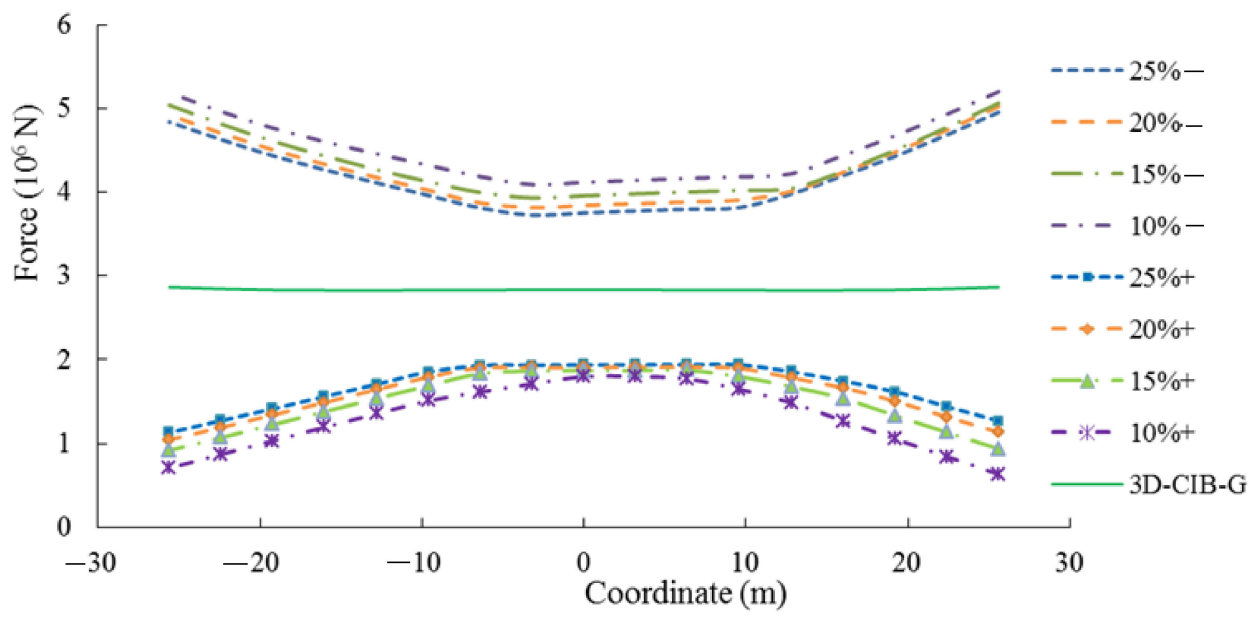

Figure 18. Comparison of the peak axial force of the 3D-CIBs along $Y$-axis.

\section{Conclusions}

This study aimed at evaluating the influence of different vertical equivalent damping ratios of 3D-CIB on the seismic response and isolation effectiveness, with four vertical equivalent damping ratios assumed. A comparison analysis of seismic response in terms of the FRS, peak acceleration, displacement response of a nuclear reactor building, and dynamic response of a 3D-CIB was performed. It was found that: (1) the horizontal FRS is slightly influenced by the vertical equivalent damping ratio of the $3 \mathrm{D}-\mathrm{CIB}$, whereas the increase of the vertical equivalent damping ratio has a significant effect on reducing the vertical FRS; (2) the peak vertical acceleration increased with the decrease in the vertical equivalent damping ratios of the $3 \mathrm{D}-\mathrm{CIB}$, and the difference of peak accelerations calculated by the damping ratios of 20 and $25 \%$ is within $10 \%$; (3) the increase of the vertical equivalent damping ratio is capable of reducing the horizontal displacement and the rocking effect of the superstructure, and effectively controlling the vertical displacement amplitude. When the vertical equivalent damping ratio was 15 and $20 \%$, the horizontal displacement and the rocking ratio of the superstructure was $5 \sim 12 \%$ higher than the corresponding results of $25 \%$, and the vertical compression displacement of the 3D-CIB is increased by within $8 \%$; (4) the vertical equivalent damping ratio of the 3D-CIB has a slight effect on its axial force. Consequently, it was demonstrated that the increase of vertical equivalent damping ratio is advantageous for isolation effectiveness. From the point of view of displacement control, it is suggested that a 3D-CIB with the vertical equivalent damping ratio of $15 \sim 20 \%$ is appropriate and acceptable. Since rocking motion is inevitable for the 3D base-isolated structure, and excessive rocking motion is undesired and should be suppressed for NPPs, the study of a rocking suppression device will be carried out in the future.

Author Contributions: Conceptualization, X.Z. and G.L; methodology, X.Z. and J.L.; software, X.Z.; validation, X.Z.; writing — original draft preparation, X.Z. and J.L.; writing-review and editing, G.L. and R.P. All authors have read and agreed to the published version of the manuscript.

Funding: This research was funded by the National Science and Technology Major Project of advanced technology research on the structural health inspection and evaluation of nuclear power plants (Grant No. 2018ZX06002008). This financial support is gratefully acknowledged.

Institutional Review Board Statement: Not applicable.

Informed Consent Statement: Not applicable.

Data Availability Statement: Not applicable. 
Conflicts of Interest: The authors declare no conflict of interest.

\section{References}

1. Shrimali, M.; Jangid, R.; Shrimali, M.; Jangid, R. Earthquake response of isolated elevated liquid storage steel tanks. J. Constr. Steel Res. 2003, 59, 1267-1288. [CrossRef]

2. Petti, L.; Giannattasio, G.; De Iuliis, M.; Palazzo, B. Small scale experimental testing to verify the effectiveness of the base isolation and tuned mass dampers combined control strategy. Smart Struct. Syst. 2010, 6, 57-72. [CrossRef]

3. Castaldo, P.; Palazzo, B.; Alfano, G.; Palumbo, M.F. Seismic reliability-based ductility demand for hardening and softening structures isolated by friction pendulum bearings. Struct. Control. Health Monit. 2018, 25, e2256. [CrossRef]

4. Kelly, J. Analysis of the run-in effect in fiber-reinforced isolators under vertical load. J. Mech. Mater. Struct. 2008, 3, 1383-1401. [CrossRef]

5. De Domenico, D.; Ricciardi, G. Earthquake-resilient design of base isolated buildings with TMD at basement:Application to a case study. Soil Dyn. Earthq. Eng. 2018, 113, 503-521. [CrossRef]

6. De Domenico, D.; Gandelli, E.; Quaglini, V. Effective base isolation combining low-friction curved surface sliders and hysteretic gap dampers. Soil Dyn. Earthq. Eng. 2020, 130, 105989. [CrossRef]

7. Markou, A.; Stefanou, G.; Manolis, G.D. Stochastic response of structures with hybrid base isolation systems. Eng. Struct. 2018, 172, 629-643. [CrossRef]

8. De Luca, A.; Guidi, L.G. Base isolation issues in Italy: Integrated architectural and structural designs. Soil Dyn. Earthq. Eng. 2020, 130, 105912. [CrossRef]

9. De Luca, A.; Guidi, L.G. State of art in the worldwide evolution of base isolation design. Soil Dyn. Earthq. Eng. 2019, 125, 105722. [CrossRef]

10. Rahnavard, R.; Thomas, R.J. Numerical evaluation of steel-rubber isolator with single and multiple rubber cores. Eng. Struct. 2019, 198, 109532. [CrossRef]

11. Rahnavard, R.; Craveiro, H.D.; Napolitano, R. Static and dynamic stability analysis of a steel-rubber isolator with rubber cores. Structures 2020, 26, 441-455. [CrossRef]

12. Sheikhi, J.; Fathi, M.; Rahnavard, R. Natural rubber bearing incorporated with high toughness steel ring dampers. Structures 2020, 24, 107-123. [CrossRef]

13. Sheikhi, J.; Fathi, M.; Rahnavard, R.; Napolitano, R. Numerical analysis of natural rubber bearing equipped with steel and shape memory alloys dampers. Structures 2021, 32, 1839-1855. [CrossRef]

14. Altabani, D.; Hejazi, F.; Rashid, R.; Aziz, F. Development of new rectangular rubber isolators for a tunnel-form structure sub-jected to seismic excitations. Structures 2021, 32, 1522-1542. [CrossRef]

15. Radkia, S.; Rahnavard, R.; Tuwair, H.; Gandomkar, F. Investigating the effects of seismic isolators on steel asymmetric structures considering soil-structure interaction. Structures 2020, 27, 1029-1040. [CrossRef]

16. Coladant, C. Seismic isolation of nuclear power plants-EDF's philosophy. Nucl. Eng. Des. 1991, 127, 243-251. [CrossRef]

17. Frano, R.L. Benefits of Seismic Isolation for Nuclear Structures Subjected to Severe Earthquake. Sci. Technol. Nucl. Install. 2018, 8017394. [CrossRef]

18. Whittaker, A.S.; Kumar, M. Seismic Isolation of Nuclear Power Plant. Nucl. Eng. Technol. 2014, 46, 569-580. [CrossRef]

19. Whittaker, A.S.; Sollogoub, P.; Kim, M.K. Seismic isolation of nuclear power plants: Past, present and future. Nucl. Eng. Des. 2018, 338, 290-299. [CrossRef]

20. Frano, R.L.; Forasassi, G. Isolation systems influence in the seismic loading propagation analysis applied to an innovative near term reactor. Nucl. Eng. Des. 2010, 240, 3539-3549. [CrossRef]

21. Zhao, C.; Chen, J. Numerical simulation and investigation of the base isolated NPPC building under three directional seismic loading. Nucl. Eng. Des. 2013, 265, 484-496. [CrossRef]

22. Wang, D.; Zhuang, C.; Zhang, Y. Seismic response characteristics of base-isolated AP1000 nuclear shield building subjected to beyond-design basis earthquake shaking. Nucl. Eng. Technol. 2018, 50, 170-181. [CrossRef]

23. Zhou, Z.; Wong, J.; Mahin, S. Potentiality of Using Vertical and Three-Dimensional Isolation Systems in Nuclear Structures. Nucl. Eng. Technol. 2016, 48, 1237-1251. [CrossRef]

24. Suhara, J.; Matsumoto, R.; Oguri, S.; Okada, Y.; Inoue, K.; Takahashi, K. 3-D seismic isolation device with rolling seal type air spring. In Proceedings of the 18th International Conference on Structural Mechanics in Reactor Technology (SMiRT18), Beijing, China, 7-12 August 2005; pp. 3381-3391.

25. Suhara, J.; Tamura, T.; Okada, Y.; Umeki, K. Development of Three Dimensional Seismic Isolation Device With Laminated Rubber Bearing and Rolling Seal Type Air Spring. In Proceedings of the Fatigue, Fracture and Damage Analysis; ASME International, Vancouver, BC, Canada, 5-9 August 2002; pp. 43-48.

26. Kashiwazaki, A.; Shimada, T.; Fujiwaka, T.; Moro, S. Study on 3-dimensional base isolation system applying to new type power plant reactor. In Proceedings of the Transaction of the 17th International Conference on Structural Mechanics in Reactor Technology SMiRT17, Prague, Czech Republic, 17-22 August 2003; pp. 2295-2302.

27. Kitamura, S.; Okamura, S.; Takahashi, K. Experimental Study on Vertical Component Seismic Isolation System With Coned Disk Spring. In Proceedings of the Volume 7: Operations, Applications, and Components; ASME International, Denver, CO, USA, 17-21 July 2005; pp. 175-182. 
28. Kitamura, S.; Morishita, M.; Moro, S. Study on Vertical Component Seismic Isolation System With Coned Disk Spring. Aging Manag. Licens. Renew. 2004, 2, 21-28. [CrossRef]

29. Morishita, M.; Kitamura, S.; Moro, S.; Kamishima, Y.; Somaki, T. Study on 3-dimensional seismic isolation system for next generation nuclear power plant-vertical component isolation system with coned disk spring. In Proceedings of the 13th World Conference on Earthquake Engineering (ASME), Vancouver, BC, Canada, 1-6 August 2004. Paper No. 620.

30. Wang, W.; Wang, X. Tests, model, and applications for coned-disc-spring vertical isolation bearings. Bull. Earthq. Eng. 2019, 18, 357-398. [CrossRef]

31. Zhao, Y.; Su, J.; Lu, M.; Yu, Y. Mechanical performance test of combined 3-dimensional isolation bearing for 3-dimensional baseisolated buildings. In Proceedings of the Tenth Pacific Conference on Earthquake Engineering. Building an Earthquake-Resilient Pacific Earthquake, Sydney, Australia, 6-8 November 2015.

32. Almen, J.O.; Laszlo, A. The Uniform-Section Disc Spring, Transactions of American Society of Mechanical Engineers. 1936. Available online: https:/ / www.shotpeener.com/library/pdf/1935000.pdf (accessed on 8 May 2021).

33. China National Standardization Management Committee. Disc Spring (GB/T1972-2005), 2005. Available online: https:/ /www. chinesestandard.net/PDF/English.aspx/GBT1972-2005 (accessed on 8 May 2021).

34. U.S. Nuclear Regulatory Commission. RG 1.60, Rev.1. Design Response Spectra for Seismic Design of Nuclear Power Plants. Washington, DC, 1973. Available online: https://www.nrc.gov/docs/ML0037/ML003740207.pdf (accessed on 8 May 2021).

35. U.S. Nuclear Regulatory Commission. RG 1.92, Rev.2. Combining Modal Responses and Spatial Components in Seismic Response Analysis. Washington, DC, 2006. Available online: https://www.nrc.gov/docs/ML0532/ML053250475.pdf (accessed on 8 May 2021). 